Boise State University

ScholarWorks

Geosciences Faculty Publications and

Presentations

Department of Geosciences

6-2017

\title{
Aerodynamic Roughness Length Estimation with Lidar and Imaging Spectroscopy in a Shrub-Dominated Dryland
}

\author{
Aihua Li \\ Boise State University \\ Wenguang Zhao \\ University of Idaho \\ Jessica J. Mitchell \\ Appalachian State University \\ Nancy F. Glenn \\ Boise State University \\ Matthew J. Germino \\ US Geological Survey, Forest and Rangeland Ecosystem Science Center
}

See next page for additional authors

This document was originally published in Photogrammetric Engineering \& Remote Sensing by the American

Society for Photogrammetry and Remote Sensing. Copyright restrictions may apply. doi: 10.14358/PERS.83.6.415 


\section{Authors}

Aihua Li, Wenguang Zhao, Jessica J. Mitchell, Nancy F. Glenn, Matthew J. Germino, Joel B. Sankey, and Richard G. Allen 


\title{
Aerodynamic Roughness Length Estimation with Lidar and Imaging Spectroscopy in a Shrub-Dominated Dryland
}

\author{
Aihua Li, Wenguang Zhao, Jessica J. Mitchell, Nancy F. Glenn, Matthew J. Germino, Joel B. Sankey, and Richard G. Allen
}

\begin{abstract}
The aerodynamic roughness length $\left(Z_{0 m}\right)$ serves an important role in the flux exchange between the land surface and atmosphere. In this study, airborne lidar (ALS), terrestrial lidar (TLS), and imaging spectroscopy data were integrated to develop and test two approaches to estimate $Z_{0 m}$ over a shrub dominated dryland study area in south-central Idaho, USA. Sensitivity of the two parameterization methods to estimate $Z_{0 m}$ was analyzed. The comparison of eddy covariancederived $Z_{0 m}$ and remote sensing-derived $Z_{0 m}$ showed that the accuracy of the estimated $Z_{0 m}$ heavily depends on the estimation model and the representation of shrub (e.g., Artemisia tridentata subsp. wyomingensis) height in the models. The geometrical method (RA1994) led to 9 percent $(\sim 0.5 \mathrm{~cm})$ and $25 \%(\sim 1.1 \mathrm{~cm})$ errors at site 1 and site 2 , respectively, which performed better than the height variability-based method (MR1994) with bias error of 20 percent and 48 percent at site 1 and site 2, respectively. The RA1994 model resulted in a larger range of $Z_{0 m}$ than the MP1994 method. We also found that the mean, median and 75 th percentiles of heights (H75) from ALS provides the best $Z_{0 m}$ estimates in the MR1994 model, while the mean, median, and MAD (Median Absolute Deviation from Median Height), as well as AAD (Mean Absolute Deviation from Mean Height) heights from ALS provides the best $Z_{0 m}$ estimates in the RA1994 model. In addition, the fractional cover of shrub and grass, distinguished with ALS and imaging spectroscopy data, provided the opportunity to estimate the frontal area index at the pixel-level to assess the influence of grass and shrub on $Z_{0 m}$ estimates in the RA1994 method. Results indicate that grass had little effect on $Z_{0 m}$ in the RA1994 method. The $Z_{0 m}$ estimations were tightly coupled with vegetation height and its local variance for the shrubs. Overall, the results demonstrate that the use of height and fractional cover from remote sensing data are promising for estimating $Z_{0 m}$, and thus refining land surface models at regional scales in semiarid shrublands.
\end{abstract}

Aihua Li and Nancy F. Glenn are with the Department of Geoscience, Boise State University, 1920 University Drive, Boise ID 83725 (nancyglenn@bosiestate.edu).

Jessica J. Mitchell is with the Department of Geography and Planning, Appalachian State University, Boone NC.

Matthew J. Germino is with the US Geological Survey, Forest and Rangeland Ecosystem Science Center, Boise, ID.

Joel B. Sankey is with the US Geological Survey, Grand Canyon Monitoring and Research Center, Flagstaff, AZ.

Wenguang Zhao and Richard Allen are with Biological Engineering, University of Idaho, Kimberly, ID.

\section{Introduction}

The roughness of the land surface plays an important role in the flux exchange between the land surface and atmosphere (Sud et al., 1988; Prueger et al., 2004). Land surface roughness can be characterized by the aerodynamic roughness length $\left(Z_{0 m}\right)$, which is the height of roughness elements at which the mean wind speed approaches zero given the extrapolation of the logarithmic wind profile (Garratt, 1992; Kaimal and Finnigan, 1994). In dryland ecosystems, such as semiarid shrublands, the spatial distribution of roughness elements and specifically $Z_{0 m}$ are key parameters for physical models of aeolian transport and for estimating dust emissions from wind erosion (Prigent et al., 2005; Sankey et al., 2010; Sankey et al., 2013; Nield et al., 2013; Pelletier and Field, 2016) and for land surface models (Dickinson and Henderson-Sellers, 1988; Jasinski and Crago, 1999).

Traditionally, $Z_{0 m}$ is calculated using the Monin-Obukhov similarity theory (MOST) applied to measurements of horizontal wind speed profiles (Garratt, 1994; Kustas et al., 1994). Therefore, $Z_{0 m}$ can be obtained through observations by an eddy covariance (EC) system which provides meteorological measurements; however, estimating $Z_{0 m}$ from $\mathrm{EC}$ is restricted to a single value in the source area of the EC tower, and thus EC estimates are limited for regional land surface models (Paul-Limoges et al., 2013). To address this issue, studies have used remotely sensed information, such as scatterometer (Prigent et al., 2005) and bi-directional reflectance (Marticorena et al., 2004) data, along with laser altimeter measurements (Menenti and Ritchie, 1994; De Vries et al., 2003, Colin and Faivre, 2010, Weligepolage et al., 2012) for parameterizing $\mathrm{Z}_{0 \mathrm{~m}}$ over a local or regional scale. Aerodynamic roughness is influenced by the height, geometry, density and pattern of roughness elements which include vegetation and microand macro-topographic features (Garratt, 1992; Lettau, 1969; Raupach, 1992 and 1994; Shaw and Pereira, 1982). Empirical relationships between $Z_{0 m}$ and measurable characteristics of roughness elements (e.g., vegetation height, normalized difference vegetation index (NDVI), leaf area index (LAI), frontal area index (FAI, $\left.\lambda_{f}\right)$ ) have been used to parameterize $Z_{0 m}$ over a large sale. For example, NDVI and LAI derived from optical remote sensing have been correlated with $Z_{0 m}$ (Choudhury and Monteith, 1988; Bastiaanssen, 1995; Jia et al., 2003). In some previous studies, $Z_{0 m}$ was assumed as a proportion of roughness element height (i.e., Kustas et al., 1989; Garratt, 1992). The three-dimensional (3D) structure of the land's surface and vegetation, as captured by laser altimetry (or light detection and ranging (lidar)) provides a straightforward measure of

Photogrammetric Engineering \& Remote Sensing Vol. 83, No. 6, June 2017, pp. 415-427. $0099-1112 / 17 / 415-427$

(C) 2017 American Society for Photogrammetry and Remote Sensing doi: 10.14358/PERS.83.6.415 
roughness element height across the landscape. Tian et al. (2011) combined lidar-derived forest structural variables (tree height, first branch height, crown width, and stand density) and SPOT5-derived LAI to parameterize $Z_{0 m}$ in a forested environment. They concluded that $Z_{0 m}$ estimates derived from lidar are more accurate than those derived from satellite optical remote sensing data. Menenti and Ritchie (1994) computed $\mathrm{Z}_{0 \mathrm{~m}}$ based on the geometrical regularity of vegetation canopies using lidar-derived vegetation heights (average and standard deviations). This method was adapted by Brown and Hugenholtz (2012) for $Z_{0 m}$ estimates in a mixed grassland prairie and further assessed by Paul-Limoges et al. (2013) in a harvested Douglas-fir forest. Colin and Faivre (2010) estimated $Z_{0 m}$ based on a geometrical model using lidar-derived height and wind profile information and concluded that the geometrical model could provide comparable results on natural heterogeneous land covers present in the region, including sparse grassland and low tree land cover types.

While some previous studies have demonstrated that lidar is well-suited for deriving $\mathrm{Z}_{0 \mathrm{~m}}$ (e.g., Brown et al., 2012; Hugenholtz et al., 2013; Paul-Limoges et al., 2013), there are practical limitations of deriving structural information in shrublands from lidar, and in particular airborne lidar. These limitations include underestimation of height and difficulty in deriving individual roughness element canopies (Hopkinson et al., 2005; Glenn et al., 2011; Mitchell et al., 2012). Variables derived from complementary airborne imaging spectroscopy (aka hyperspectral) data may be necessary, particularly if the combination with lidar is capable of improved vegetation cover estimates (Mitchell et al., 2015), which are relatable to shrub density.

In this paper we develop an optimized processing flow that uses high resolution, remotely sensed optical and 3D datasets to spatially extend $Z_{0 m}$ mapping over a semiarid landscape dominated by the open canopy, low stature, and sparse vegetation ( $<25$ percent canopy cover). This landscape is representative of approximately 62 million ha of sagebrush steppe in the Great Basin, western US. Resolving differences in $Z_{0 m}$ at the landscape scale with remote sensing techniques has the potential to improve energy balance estimates in hydrologic and ecologic models in this and similar dryland ecosystems (Allen et al., 2011; Paul et al. 2014). Two existing models of estimating $Z_{0 m}$ were evaluated: the height variability model of Menenti and Ritchie (1994) (hereafter, MR1994) and the wind profile model developed by Raupach (1994) (hereafter, RA1994). We chose these two models amongst those listed in Table 1 because they are suitable for use in sparse vegetation (Menenti and Ritchie, 1994; Raupach, 1994;

Table 1. Common $Z_{o m}$ Parameterization Methods with Input Parameters

\begin{tabular}{lllll}
\hline References & Parameters & Equations & Strength & Weakness \\
\hline Garratt (1994) & Height & $z_{0 m}=a h$ & The simplest method. & $\begin{array}{l}\text { Only height is taken } \\
\text { into account. }\end{array}$ \\
\hline $\begin{array}{l}\text { Lettau (1969) } \\
\text { Height and } \\
\text { frontal index }\end{array}$ & $Z_{0 m}=0.5 h \lambda_{f}$ & $\begin{array}{l}\text { Most appropriate in vegetation } \\
\text { where the roughness elements } \\
\text { are very evenly spaced. }\end{array}$ & $\begin{array}{l}\text { It is not suitable for } \\
\text { roughness elements } \\
\text { with high density. }\end{array}$ \\
\hline $\begin{array}{l}\text { Menenti and } \\
\text { Ritchie (1994) }\end{array}$ & Height & $Z_{0 m}=1 / N \Sigma\left[\sigma_{h, j} / h_{f}\right] * \bar{h}$ & Empirical model. & Only height is taken \\
into account.
\end{tabular}

$\begin{array}{lll}\text { Reight, } & \frac{Z_{0 m}}{h_{v}}=\left(1-\frac{d_{0}}{h_{v}}\right) \cdot \exp \left(-k \frac{U}{u_{*}}+\varphi_{h}\right) & \begin{array}{l}\text { For sparse vegetation areas } \\ \text { frontal index, }\end{array} \\ \begin{array}{l}\text { meteorological } \\ \text { measurements }\end{array} & \frac{d_{0}}{h_{v}}=1-\frac{1-\exp \left[-\left(C_{d l} 2 \lambda_{f}\right)^{0.5}\right]}{\left(C_{d l} 2 \lambda_{f}\right)^{0.5}} & \begin{array}{l}\text { It is complex and } \\ \text { needs many input } \\ \text { parameters. }\end{array}\end{array}$

$$
\begin{aligned}
& \frac{d}{h}=1+\alpha^{-\lambda_{p}}\left(\lambda_{p}-1\right) \\
& \frac{z_{0 \pi n}}{h}=\left(1-\frac{d}{h}\right) \exp \left[-\left(0.5 \beta \frac{C_{D}}{k^{2}}\left(1-\frac{d}{h}\right) \lambda_{f}\right)^{-0.5}\right]
\end{aligned}
$$

Height and frontal index
For heterogeneous land surface and urban regions; Can explain the direction of airflow.
It is complex and needs many input parameters.

\section{Bastiaanssen}

(1998)
NDVI

$$
z_{0 m} \exp (a+b N D V I)
$$

The model has limits on different vegetation types and results sensitive to plant phenology.
Choudhury and Monteith (1988)
LAI, height

$$
d=h\left[\ln \left(1+X^{1 / 6}\right)+0.03 \ln \left(1+X^{6}\right)\right]
$$

$Z_{0 m}= \begin{cases}Z_{0 s}+0.28 h X^{1 / 2} & \text { for } 0 \leq X \leq 0.2 \\ 0.3 h(1-d / h) & \text { for } 0.2<X \leq 2\end{cases}$

Applied at regional scales.

$X=0.2 \mathrm{LAI}$
The model has limits on different vegetation types and results sensitive to plant phenology. 
Brown and Hugenholtz, 2012). In addition, the models' input variables are suitable to derive from remote sensing data and subsequently allow us to explore the use of lidar and optical hyperspectral data for estimating aerodynamic roughness length. MR1994 is an empirical model and can be implemented by utilizing the roughness element height and its standard deviation. The RA1994 is a geometrical model based on the wind velocity profile and accounts for height and density of roughness elements (FAI, discussed in more detail below). Our objectives were to (a) explore an optimal $\mathrm{Z}_{0 m}$ estimation model for the shrub-steppe landscape studied herein; (b) quantify the sensitivity of the main driving parameters in the $Z_{0 m}$ estimation models; and (c) evaluate the potential advantages and limitations of integrating lidar and imaging spectroscopy data for parameterizing $Z_{0 m}$ over a larger, regional area.

\section{Experimental Site and Data}

\section{Site Description}

The study site is located southwest of Hollister, Idaho $\left(42^{\circ} 19^{\prime} 26.56^{\prime \prime} \mathrm{N}, 114^{\circ} 42^{\prime} 3.29^{\prime \prime} \mathrm{W}\right)$. The site was bound on either end by a scintillometer transmitter and receiver, and between them at even spacing were two eddy covariance (EC) stations (Figure 1). The plant community consists primarily of Wyoming Big Sagebrush (Artemesia tridentata ssp wyomingensis) with an understory of native grasses and cheatgrass (Bromus tectorum). The sagebrush heights range from 0.01 to $1 \mathrm{~m}$ with mean $(\mathrm{SD})$ of $0.11 \mathrm{~m}(0.04 \mathrm{~m})$. Soils are shallow and are interspersed with basalt rocks (not protruding more than a few to $10 \mathrm{~cm}$ above ground). The elevation ranges from 1,410 to $1,450 \mathrm{~m}$ with a mean of $1,426 \mathrm{~m}$ and standard deviation of $9.5 \mathrm{~m}$. The sagebrush canopy cover is relatively homogenous with 25 percent mean shrub cover (derived from hyperspectral and lidar, see below) at a several $\mathrm{m}^{2}$ scale across the 1 to 2 $\mathrm{km}$ transect.

\section{Meteorological Data}

Measurements from the two EC flux towers such as wind direction and speed, and sensible heat flux have been collected every half-hour since 2009. Meteorological measurements have been collected with several 3D sonic anemometers dispersed across the footprint (turbulent source area) (RMYoung and CSAT). In addition, the site was instrumented in several locations to collect measurements of soil moisture, temperature, and heat flux. Meteorological measurements collected over two time frames were used for in-situ $\mathrm{Z}_{0 m}$ calculation and source area analysis. $Z_{0 m}$ was estimated on 05,06 , and $14 \mathrm{Au}$ gust 2010, corresponding to the lidar and imaging spectroscopy data collection. A multi-year period (2009 to 2010) was also used to provide an average estimate of $Z_{0 m}$ over a longer timeframe. The analysis over this period assumed limited shrub growth, typical of sagebrush-dominated regions (e.g., Watts and Wambolt, 1996). The original $20 \mathrm{~Hz}$ binary EC data were subjected to QA/QC (Quality Assurance and Quality Control) procedures that included sufficient power for instrument operation $(>10 \mathrm{~V})$; erroneous measurements disrupted by raindrops; wind direction from the backside of the CSAT3 sonic anemometers; removal of outlier data identified by comparing data from multiple co-located sensors, and spike removal. The EC data were adjusted to synchronize data from different types of sensors, using coordinate rotation of $3 \mathrm{D}$ wind data (Lee et al., 2004) and correction of density effects on sensible and latent heat transfer (Webb et al., 1980). The final samples of EC data were used to determine $\mathrm{Z}_{0 m}$ under stable, unstable, and near-neutral conditions.

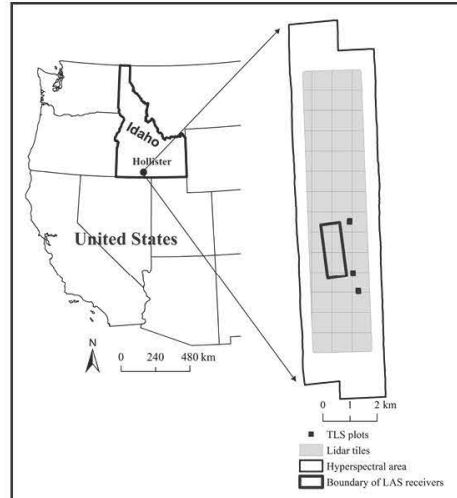

(a)

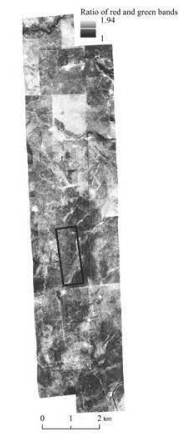

(c)

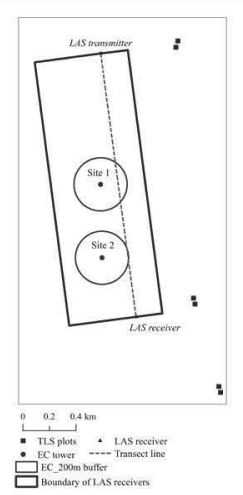

(b)

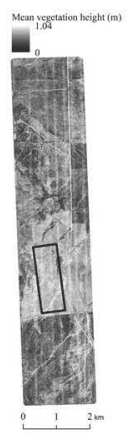

(d)
Figure 1. (a) The study area near Hollister, Idaho, USA; (b) a zoom of the right panel of (a); (c) The ratio of red and green bands from hyperspectral data; (d) the mean vegetation height from lidar. The boundary of LAS receivers is the focal area of this study. Sites 1 and 2 are the locations of the EC towers. The transect line is a large aperture scintillometer transect and the dark circles are the $200 \mathrm{~m}$ buffer around the sites.

\section{Remote Sensing Data}

In this paper, remote sensing data include airborne lidar (ALS), terrestrial laser scanning (TLS) and imaging spectroscopy data. (see Table 2). Lidar was used to derive the height-related information for the roughness elements (shrub and grass vegetation) and the digital elevation model (DEM). The hyperspectral data were combined with lidar for estimating percent cover of the roughness elements, which is approximate to the roughness element density and can be used for the frontal area index (FAI) calculation. TLS data were also collected to calibrate the underestimation of vegetation height by ALs. Heights from TLS have been shown to have a nearly perfect agreement with field-measured sagebrush heights due to the ground-based collection method of TLS (Li et al., 2015). Small footprint ALS data were acquired using a dual-mounted Leica ALS50 Phase II sensor onboard a Cessna Caravan 208B operated by Quantum Spatial, Inc., Corvallis, Oregon. The lidar data were collected on 05 and 06 August 2010, using a wavelength of 1064 $\mathrm{nm}$ and a resultant average point density of 7 points per $\mathrm{m}^{2}$. The TLS data were collected in the near infrared $(1550 \mathrm{~nm})$ with a Riegl VZ-1000 (Riegl, Horn, Austria) instrument with a scan range of approximately $1 \mathrm{~km}$ and a beam divergence of $0.3 \mathrm{mrad}$. The TLS data were collected in fall 2011 and 2012. Six plots, $30 \mathrm{~m}$ by $30 \mathrm{~m}$ each, were established and scanned using a TLS positioned on a tripod $2 \mathrm{~m}$ above the ground. Imaging spectroscopy data were collected 14 August 2010, with the HyMap sensor (operated by HyVista, Inc., Sydney, Australia), which collects calibrated radiance data in 126 near-contiguous spectral bands ( $450-2480 \mathrm{~nm}$ ) that range in 
width from $15 \mu \mathrm{m}$ in the visible and near infrared to $20 \mu \mathrm{m}$ in the shortwave infrared (Cocks et al., 1998) at a pixel resolution of $3.125 \mathrm{~m}$ by $3.125 \mathrm{~m}$.

Table 2. Remote Sensing and Eddy Covariance Data Sets Used in the Study

\begin{tabular}{|c|c|c|}
\hline Data sets & Acquisition Date & Characteristics \\
\hline $\begin{array}{l}\text { Terrestrial } \\
\text { lidar }\end{array}$ & $\begin{array}{l}\text { Sept. } 2011 \\
\text { and } 2012\end{array}$ & $\begin{array}{l}\text { Average point density of } 10,000 \\
\text { points per } \mathrm{m}^{2} \text { at six plots, each } \\
30 \mathrm{~m} \text { by } 30 \mathrm{~m} \text {. Scanning occurred } \\
\text { from a } 2 \mathrm{~m} \text { tripod. }\end{array}$ \\
\hline Airborne lidar & $\begin{array}{l}05 \text { and } 06 \\
\text { Aug } 2010\end{array}$ & $\begin{array}{l}\text { Average point density of } 7 \text { points } \\
\text { per } \mathrm{m}^{2}\end{array}$ \\
\hline Hyperspectral & 14 Aug 2010 & $\begin{array}{l}3 \mathrm{~m} \text { resolution, } 450-2500 \mathrm{~nm} \\
\text { wavelengths }\end{array}$ \\
\hline $\begin{array}{l}\text { Eddy } \\
\text { Covariance }\end{array}$ & $\begin{array}{l}05,06 \text { and } 14 \\
\text { Aug } 2010\end{array}$ & $\begin{array}{l}\text { RMYoung and CSAT sensors } \\
\text { Site 1: } \\
\text { Main wind direction: } 173^{\circ} \\
\text { Main wind speed: } 5.2 \mathrm{~m} / \mathrm{s} \\
\text { Site 2: } \\
\text { Main wind direction: } 183^{\circ} \\
\text { Main wind speed: } 5.3 \mathrm{~m} / \mathrm{s}\end{array}$ \\
\hline
\end{tabular}

\section{Methods}

In our study, FAI and vegetation heights are the main variables derived from the remotely sensed data for $\mathrm{Z}_{0 m}$ estimation. The percent cover of vegetation (PVC) that represented the cover percentage of roughness elements was derived from a combination of lidar and imaging spectroscopy data and then used for FAI calculation. In order to test the sensitivity of height in the models, a range of different height metrics were compared to obtain the optimal height statistics in the $\mathrm{Z}_{0 m}$ estimation models. Additionally, we calibrated ALS-derived mean vegetation heights with TLS-derived mean vegetation heights. This was performed to address the possible underestimation of mean vegetation heights from ALS and to assess the effectiveness of ALS-derived mean vegetation height in $\mathrm{Z}_{0 m}$ estimation models. The calibrated heights were also used in the two $\mathrm{Z}_{0 \mathrm{~m}}$ estimation models to assess whether the calibrated heights improved the estimates. We evaluated the sensitivity of the $\mathrm{Z}_{0 m}$ estimation based on the spatial scale at which height variability is calculated in the MR1994 model. To evaluate the sensitivity of FAI in the RA1994 model, two FAI calculation methods were compared. The workflow is shown in Figure 2.

\section{Vegetation Height Metrics and DEM Derived from Lidar}

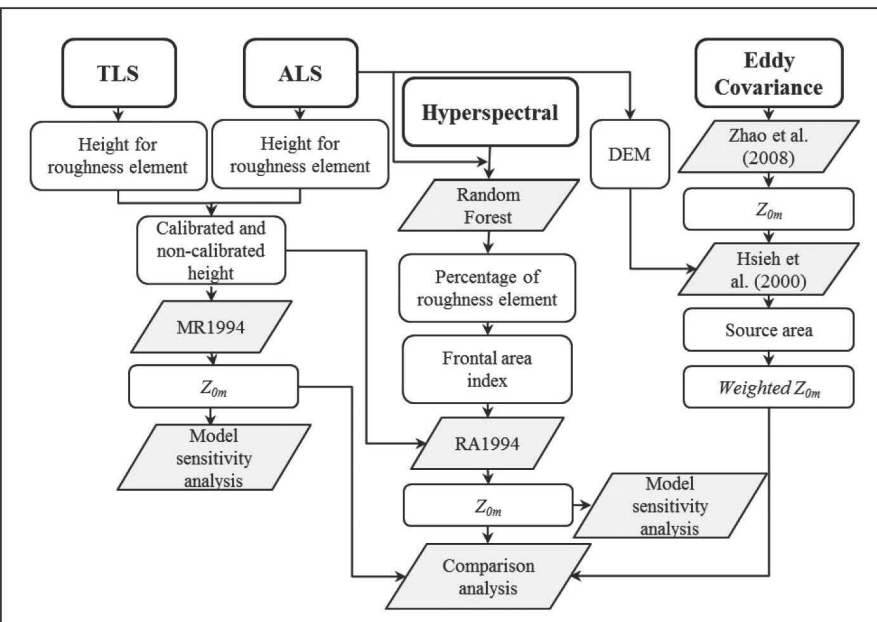

Figure 2. Workflow diagram.
The TLS data were registered, cleaned (removal of noise points) and height filtered in the RiSCAN Pro software package (Riegl GmbH, Horn, Austria) and BCAL Lidar Tools (Streutker and Glenn, 2006; http://bcal.boisestate.edu/tools/ lidar/). The ALS data were height filtered with the BCAL Lidar Tools. Both ALS and TLS were height filtered using $5 \mathrm{~m}$ and 50 $\mathrm{cm}$ canopy spacing, respectively, a $5 \mathrm{~cm}$ ground threshold, nearest neighbor interpolation, and 50 iterations (Streutker and Glenn, 2006). We then transformed the height filtered lidar point data to raster products. Eight $(n=8)$ vegetation height metrics (Table 3 ) were rasterized at seven resolutions $(0.5,1,3,5,10,15,30 \mathrm{~m})$ from both the TLS and ALS data. The ALS-derived mean height had up to a 30 percent underestimation of the mean vegetation heights from TLS data, which is in agreement with previous studies in sagebrush-steppe communities from airborne lidar (Streutker and Glenn, 2006; Glenn et al., 2011; Mitchell et al., 2011). Therefore, the ALs-derived mean height was calibrated and scaled with the TLS-derived mean height. The eight ALS-derived raster height-related products and the calibrated mean height were then used in the MR1994 and RA1994 models for $Z_{0 m}$ calculations. The RA1994 method was conducted at $3 \mathrm{~m}$ resolution to match the resolution of imaging spectroscopy data. The MR1994 method used the lidar data only and was tested at varying resolutions (see below). The RA1994 and MR1994 models were compared at $3 \mathrm{~m}$ resolution. Correspondingly, a DEM at $3 \mathrm{~m}$ resolution from the ALS data was generated for the source area analysis to compare the EC-based $Z_{0 m}$ with the remote sensing estimated $\mathrm{Z}_{0 m}$ maps.

Table 3. Height Metrics from Lidar Data

\begin{tabular}{ll}
\hline $\begin{array}{l}\text { Lidar } \\
\text { variables }\end{array}$ & Description \\
\hline Max & Maximum height \\
\hline Mean & Mean height \\
\hline Median(H50) & Median height \\
\hline H75 & $\begin{array}{l}\text { The 75th percentile of all lidar vegetation returns } \\
\text { within a pixel }\end{array}$ \\
\hline H90 & $\begin{array}{l}\text { The 90th percentile of all lidar vegetation returns } \\
\text { within a pixel }\end{array}$ \\
\hline H95 & $\begin{array}{l}\text { The 95th percentiles of all lidar vegetation returns } \\
\text { within a pixel }\end{array}$ \\
\hline MAD & $\begin{array}{l}\text { Median Absolute Deviation (MAD) from median } \\
\text { height of all lidar vegetation returns within a pixel. } \\
\text { MAD }=1.4826 \text { * median( I height - median height I) }\end{array}$ \\
\hline AAD & $\begin{array}{l}\text { Mean Absolute Deviation (AAD) from mean height } \\
\text { of all lidar vegetation returns within a pixel. AAD }= \\
\text { mean( I height - mean height I ) }\end{array}$ \\
\hline
\end{tabular}

\section{Estimates of Cover Percentage of Roughness Elements with Lidar and} Imaging Spectroscopy Data

In this study, we used random forests (RF) (Breiman, 2001) to obtain the cover percentage (PVC) of the roughness elements (shrub and grass) from hyperspectral and lidar metrics. We then calculated the FAI from PVC for the final $\mathrm{Z}_{0 m}$ estimates. Similarly, previous studies have used spectral and lidar metrics in $\mathrm{RF}$ to predict forest canopy structural measurements (Leutner et al., 2012) and percent cover of shrub (Mitchell et al., 2015). We derived variables from the co-registered hyperspectral and ALS data to predict shrub and grass cover by adopting approaches similar to those described in Mitchell et al. (2015). The hyperspectral data were atmospherically corrected using HyMap Correction (HyCorr2) and corrected for cross-track illumination. The height filtered lidar data were rasterized to produce vegetation height raster imagery at $3 \mathrm{~m}$. The eight different vegetation height metrics were shown in Table 3. The hyperspectral and lidar imagery are co-registered 
by specifying coincident ground control points. A series of vegetation indices $(n=21)$ used in Mitchell et al. (2015) were derived from the co-registered hyperspectral. The hyperspectral-derived vegetation indices, the lidar-derived thirty-three ( $n=33$ ) vegetation metrics (see details in http://bcal.boisestate.edu/tools/lidar/), and the additional first twenty $(n=20)$ minimum noise transformed (MNF) bands from the hyperspectral data were evaluated as variables in RF for the calculation of grass and shrub cover. Nearest neighbor imputation was used to generate a spatially explicit raster response surface (Crookston and Finley, 2008) that contains predicted values for the variable of interest (e.g., shrub and grass cover) at unsampled locations.

\section{$Z_{0 m}$ Estimates with Remote Sensing Data}

\section{$Z_{\text {om }}$ Estimates Based on Height Variability by Method MR1994}

The method MR1994 parameterizes $Z_{0 m}$ based on height variability using the mean and standard deviation of vegetation height (Menenti and Ritchie, 1994) (Equation 1). Estimations of $Z_{0 m}$ from the lidar-derived heights were performed for each grid cell by using the variability in roughness heights. Two scale terms, the estimate and slice scales, are used in this method. The estimate scale is the grid cell size (spatial resolution) at which $Z_{0 m}$ is estimated and the slice scale is the segment size inside the estimate scale (Figure 3). $Z_{0 m}$ was estimated by Equation 1:

$$
z_{0 m}=1 / N \Sigma\left[\sigma_{h, i} / h_{i}\right] * \bar{h}
$$

where $Z_{0 m}$ and $\bar{h}$ are the aerodynamic roughness length estimate and the average roughness element height from lidar at the estimate scale, respectively; $N$ is the number of segments within the grid cell of the estimate scale; $\sigma_{h, j}$ is the standard deviation of the lidar-derived roughness element height in the segment $i$; and $h_{i}$ is the lidar-derived roughness element height in segment $i$.

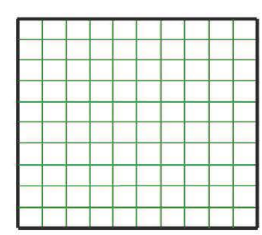

Estimate scale (pixel)

Slice scale (sub-pixel) within the estimate scale pixel

Figure 3. Schematic diagram of estimate and slice scales.

\section{Model Sensitivity}

A sensitivity analysis was performed to analyze the dependencies of MR1994 on the height and height varibility of the roughness elements. We ran eighty-eight $(n=88)$ separate analyses using different slice scales $(0.5 \mathrm{~m}$ and $1 \mathrm{~m})$ at different estimate scales $(1,3,5,10,15$, and $30 \mathrm{~m})$ for the eight different height metrics shown in Table 3.

\section{$Z_{\text {om }}$ Estimates Based on Wind Profile by Method RA1994}

The method RA1994 is based on the wind profile. The wind velocity profile over the land surface is commonly approximated by a simple logarithmic expression that assumes near neutral buoyancy conditions. The method RA1994 parameterizes $Z_{0 m}$ by combining vegetation density, height, and wind speed information in Equations 2 and 3. FAI $\left(\lambda_{f}\right)$ is the ratio of frontal surface (perpendicular to the flow) over the total surface covered by roughness elements and represents the surface roughness density (Grimmond and Oke, 1999; Burian et al., 2002), and is used in both the calculation of $d_{0}$ and $Z_{0 m}$. Notably, this method accounts for the vegetation density, but not for the distribution of roughness.

$$
\begin{gathered}
\frac{d_{0}}{h_{v}}=1-\frac{1-\exp \left[-\left(C_{d l} 2 \lambda_{f}\right)^{0.5}\right]}{\left(C_{d l} 2 \lambda_{f}\right)^{0.5}} \\
\frac{Z_{0 m}}{h_{v}}=\left(1-\frac{d_{0}}{h_{v}}\right) \cdot \exp \left(-k \frac{U}{u_{*}}+\varphi_{h}\right)
\end{gathered}
$$

with

$\frac{u_{\star}}{U}=\min \left[\left(C_{s}+C_{R} \lambda_{f}\right)^{0.5} ;\left(\frac{u_{\star}}{U}\right)_{\max }\right]$ and $\lambda_{f}=\frac{A_{f}}{A_{T}}$

where $d_{0}$ is the displacement height; $Z_{0 m}$ is the aerodynamic roughness; $h_{v}$ is vegetation (roughness element) height; $u_{*}$ is the friction velocity; $k$ is the von Karman constant; $U$ is the wind velocity; $\varphi_{h}$ is the roughness-sublayer influence function, describing the departure of the velocity profile just above the roughness from the inertial-sublayer logarithmic law; $C_{S}$ is the drag coefficient for a roughness element free surface; $C_{R}$ is the drag coefficient for an isolated roughness element; $C_{d l}$ is a free parameter; and $\left(\frac{u_{*}}{U}\right)_{\max }$ is equal to 0.2 , as calculated from the EC data in 05, 06, and 14 August 2010. Recommended values for $k, \varphi_{h}, C_{S}, C_{R}$ and $C_{d l}$ are $0.41,0.193,0.003,0.3$ and 7.5, respectively (Raupach, 1994; Colin et al., 2010).

To solve Equations 2 and 3 for $d_{0}$ and $Z_{0 m}$, one must calculate $\lambda_{f}$, which is equal to the ratio of the frontal surface area and total surface area. In this study, two methods were tested to calculate $\lambda_{f}$. The first method uses the height and the percentage of the roughness elements for $\lambda_{f}$ estimation $\left(\mathrm{F}_{\text {cover }}\right)$. The second method uses the vegetation height differences among different directions and intervals along the wind direction. The intervals are equivalent to the pixel size $\left(\mathrm{F}_{\text {section }}\right)$.

Estimation of $\lambda_{f}$ Using the Height and the Percentage of the Roughness Elements $\left(\mathbb{F}_{\text {covert }}\right)$

Calculation of $\mathrm{F}_{\text {cover }}$ assumes the roughness elements have equivalent average height and trend towards a homogeneous, compact surface. The roughness element was considered either a cuboid (Equation 4) or cylinder shape (Equation 5). $\lambda_{f}$ was estimated by the ratio of the frontal surface $\left(A_{f}\right)$ and the total surface area $\left(A_{T}\right)$. Given the height of roughness elements derived from lidar, $A_{f}$ was obtained by the roughness plane (projected) area $(A)$.

Assuming a cuboid shape of a shrub with width of $a$, $A=a^{2}$ and $A_{f}=a h$; then,

$$
\lambda_{f}=h \sqrt{P V C / A_{T}}
$$

Assuming a cylinder shape of a shrub with radius of width $r$, $A=\pi r^{2}$ and $A_{f}=2 r h$

then,

$$
\lambda_{f}=2 h \sqrt{P V C / \pi A_{T}}
$$

where $h$ is vegetation height and PVC is the percent cover of vegetation. $A_{T}$ is the total surface area and $A_{T}=$ spatial resolution $\times$ spatial resolution. We used $3 \mathrm{~m}$ spatial resolution to match the resolution of the hyperspectral data. $A$ is the area that roughness elements cover and $A=\mathrm{PVC} \times A_{T}$.

Estimation of Using Vegetation Height Differences $\left(F_{\text {sectiont }}\right)$ In the analysis we calculated $\lambda_{f}$ using a method previously adopted by Hiyama et al. (1996), De Vries et al. (2003) and Weligepolage et al. (2012). The method assumes that the land surface is isotropic and $\lambda_{f}$ can be defined over a cross-sectional line as follows (Figure 4): 


$$
\lambda_{f}=\frac{\sum \Delta y}{\sum \Delta x}
$$

where $\Delta y$ is the positive height difference for each $\Delta x$ in the cross section. In order to estimate surface features we extracted several cross sections (height at $10 \mathrm{~cm}$ intervals) along two different directions (north-south and east-west) from the generated vegetation height model.

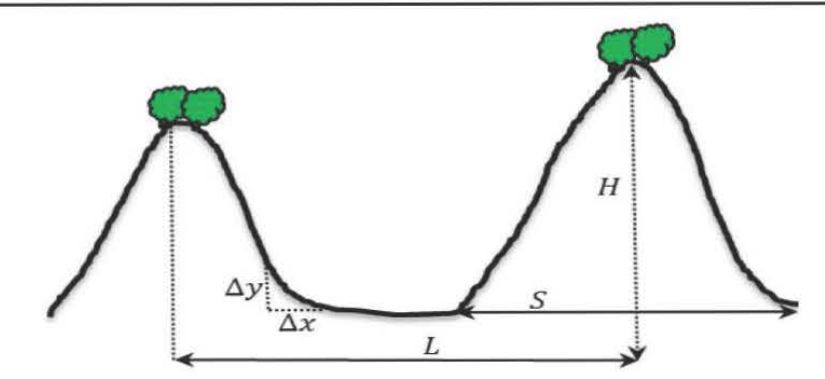

Figure 4. Schematic of land surface feature parameters. $\mathrm{H}$ is the mean height of roughness elements, $\mathrm{L}$ is the mean distance between the tops of roughness elements, and $S$ is the mean roughness element width (De Vries et al., 2003).

\section{Model Sensitivity}

We ran six separate analyses using different frontal area index calculations and shapes for shrub and grass elements to determine if the RA1994 method is sensitive to the estimation of the roughness length. These six analyses included: $\lambda_{f_{1}}$ as the $\lambda_{f}$ based on shrub cover assuming the roughness element with a cylinder shape; $\lambda_{f_{2}}$ as the $\lambda_{f}$ based on shrub cover assuming the roughness element with a cuboid shape; $\lambda_{\beta}$ as the $\lambda_{f}$ based on total vegetation cover (shrub and grass) cover assuming the roughness element with a cylinder shape; $\lambda_{f 4}$ as the $\lambda_{f}$ based on total vegetation cover (shrub and grass) cover assuming the roughness element with a cuboid shape; $\lambda_{f 5}$ as the $\lambda_{f}$ based on a cross section along a north-south (NS) direction; and $\lambda_{f 6}$ as the $\lambda_{f}$ based on a cross section along an east-west (EW) direction.

\section{Estimates with EC Measurements}

\section{Estimates with EC Measurements for Different Conditions}

$\mathrm{Z}_{0 m}$ calculated from the samples of the EC measurements was used as the reference data and was calculated as:

$$
Z_{o m}=\left(z-d_{0}\right) / \exp \left(\frac{k u}{u_{*}}+\Psi_{m}\right)
$$

Where, $z$ is the measurement height $(\mathrm{m})$; $d_{0}$ is the zero plane displacement height $(m) ; k$ is the von Karman's constant $(=0.41) ; u$ is the horizontal wind velocity $\left(\mathrm{m} / \mathrm{s}^{-1}\right)$ measured by the 3-D sonic anemometers at height $z$; $u_{*}$ is the friction velocity $\left(\mathrm{m} / \mathrm{s}^{-1}\right)$, and $\Psi_{m}$ is the stability correction for momentum. The stability correction for momentum was computed differently for stable, neutral, and unstable atmospheric conditions as (Zhao et al., 2008):

$$
\Psi_{m}=\left\{\begin{array}{cc}
-5\left(z-d_{0}\right) & \text { (under stable conditions) } \\
0 & \text { (under neutral conditions) } \\
2 \ln (1+X)+\ln \left(1+X^{2}\right)=2 \arctan (X)+\frac{\pi}{2}-3 \ln 2 & \text { (under unstable conditions) }
\end{array}\right.
$$

where, $L$ is the Monin-Obukhov length, and $X$ is a function of the Monin-Obukhov length that is expressed as:

$$
X=\left[1-16\left(\frac{z-d_{0}}{L}\right)\right]^{\frac{1}{4}}
$$

where $L>0$ and $L<0$ indicate stable and unstable conditions, respectively, and large values of $|L|$ indicate near neutral conditions (Equation 8). The Monin-Obukhov length $L$ was calculated using the equation in Ottoni (1992).

From the EC measurement data, sensible heat flux $H$ was calculated from the covariance between vertical wind velocity $w$ and sonic temperature $T\left(\overline{W^{\prime} T_{S}^{\prime}}\right)$ and then corrected with the WPL corrections (Webb et al., 1980). The friction velocity $u_{*}$ was computed from:

$$
u_{*}=\sqrt[4]{{\overline{W^{\prime} u^{\prime}}}^{2}+\overline{W^{\prime} V^{\prime}}}
$$

where, the prime represents the deviation of the instantaneous $20 \mathrm{~Hz}$ wind velocities from the mean and the over bar represents mean values over a specific time period ( 30 minutes in our case). The zero plane displacement height $d_{0}$ was estimated from a two-concentric-loop iterative method proposed by Zhao et al. (2008). In addition, site 2 had RM Young 81000 3-D anemometers but no Li-Cor LI-7500 CO2/ $\mathrm{H} 2 \mathrm{O}$ analyzer. Therefore, we were not able to perform the Webb-Pearman-Leuning (WPL) correction for the site 2 data. Thus, the estimates of $\mathrm{Z}_{0 \mathrm{~m}}$ under different atmospheric conditions was only performed at site 1 .

\section{Footprint Analyses for the Source Area Contribution to the Estimation}

The area surrounding our sensors was uniform in height and density and relatively flat for hundreds of $\mathrm{m}$ to $\mathrm{km}$, such that variations in the contributing area influencing measurements due to windspeed or direction likely caused little or no influence on our fluxes or $\mathrm{Z}_{0_{m}}$. Because the flux or $\mathrm{Z}_{0 m}$ at an eddy covariance site is a point measurement representing an upwind flux source area, the micrometeorological method provides a single estimate that is a weighted spatial average over the entire instantaneous source area (the contributing area). Yet the remote sensing data provides an estimate of $Z_{0 m}$ for each grid cell. Therefore, the footprint analyses for the source area were necessary for a direct comparison of EC and remotely sensed model $\mathrm{Z}_{0 m}$ estimates. A cumulative turbulent source area analysis proposed by Hsieh et al. (2000) was performed. This model creates a point estimate of flux contribution (flux units per $\mathrm{m}^{2}$ ) for each pixel in the raster. The total contribution from a pixel is then calculated as the product of the point estimate and pixel area. Once the pixel contribution is calculated, contour lines are created with a list of inputs. The source area is defined by contours of up to 95 percent of the cumulative contribution. The sum of the contours describes the contribution of the measured flux originating from that source. Then, a single $\mathrm{Z}_{o m}$ was derived by weighting the values in the source area (Hsieh et al., 2000; Jia et al., 2012; Bai et al., 2015), where the weights are the values from the contour lines. An additional method using the average of the estimated $\mathrm{Z}_{\mathrm{om}}$ for grid cells within a $200 \mathrm{~m}$ buffer around the EC sites was also compared.

\section{Results}

\section{Comparison of TLS-Derived Height and ALS-Derived Height}

As expected, the ALS-derived height was underestimated in comparison to the TLS-derived height (Figure 5). Only mean height was used for the TLS calibration because the mean height provides the (center) tendency of height for vegetation. A scale parameter of 1.3 was used to adjust the ALS mean height. The scaled mean height has an average bias of $-0.01 \mathrm{~m}$ and RMSE (root-mean-square error) of $0.07 \mathrm{~m}$. 


\section{Effects of Different Height Metrics on Estimation by MR1994}

For all eight height metrics except the H95 and AAD heights, a $1 \mathrm{~m}$ slice scale provided higher values of $Z_{0 m}$ than using a 0.5 $m$ slice scale (Figure 6a). Roughness length is stable at different scales for each height metric except the H95 height. The standard deviation of roughness length changes with the estimate scales. The coarser the resolution, the smaller the standard deviation, using $1 \mathrm{~m}$ or $0.5 \mathrm{~m}$ slice scales (Figure 6b). Although the H90 and H95 heights were higher than non-adjusted mean heights, they cannot be used as representative heights since they resulted in excessively high values of $Z_{o m}$. The mean, median (H50) and H75 heights led to the best approximation to in-situ $\mathrm{Z}_{0 \mathrm{~m}}$ from $\mathrm{EC}$ data when using a 0.5 slice scale.

\section{Effects of Different Vegetation Density Calculations on Estimation by the RA1994 Method}

Shrub cover was estimated with approximately 58 percent of variance explained and a RMSE of 7 percent in the RF regression model (Table 4). Grass cover had similar variance explained though the RMSE was higher (11 percent; Table 4). The percentage of shrub was estimated by MAD, IQR, and Veg_Cov from lidar, and ARI and R2G from imaging spectroscopy. The percentage of grass was estimated by MAD and IQR from lidar and the imaging spectroscopy metrics GNDVI, ARI, PSRI, MNF SWIR4, and MNF SWIR8 (see Table 5).

Calculations of FAI $\left(\lambda_{f}\right)$ based on Equations 4,5 , and 6 are shown in Table 6 . The assumed shapes resulted in small differences for FAI. When taking grass cover into account, FAI was higher than when accounting for shrub cover alone.
The calibrated height didn't change the FAI estimates when using the $F_{\text {section }}$ for the FAI calculation because the same scale parameter was used to increase the height values which were offset in the height difference ( in Equation 6); however, the calibrated height affected the FAI calculation by $\mathrm{F}_{\text {cover }}$ since another variable (PVC) was used in $\mathrm{F}_{\text {cover }}$ (Equations 4 and 5). From Table 6 , the larger the FAI, the smaller the $Z_{0 m}$; and the larger the height, the larger the $Z_{0 m}$. The predictors MAD, AAD, and median heights resulted in the closest value of $Z_{0 m}$ to the site measurement. The result demonstrates that the relationship between $Z_{0 m}$ and FAI was not simply linear. Results also indicate that height metrics influenced $Z_{0 m}$ estimates more than the different FAI calculations in RA1994 (Figure 7). We also explored the relationships between $Z_{0 m}$ estimates

Table 4. Cover Percentage Estimates with Lidar and Hyperspectral Data by RF Model. $\mathrm{R}^{2}$ and RMSE in RF Regression Model were Listed Here to Show the Accuracy of Percentage Estimate

\begin{tabular}{ccccc}
\hline Species & $\begin{array}{c}\text { Source of } \\
\text { predictor variables }\end{array}$ & $\begin{array}{c}\text { Predictor } \\
\text { variables selected }\end{array}$ & $\mathbf{R}^{2}$ & RMSE \\
\hline Shrub & lidar + hyperspectral & $\begin{array}{c}\text { MAD, IQR, } \\
\text { Veg_Cov, ARI, R2G }\end{array}$ & 0.58 & $7.35 \%$ \\
& & & \\
\hline Grass & lidar + hyperspectral & MAD, IQR, GNDVI, & 0.57 & $11.2 \%$ \\
& & ARI, PSRI, \\
& & & \\
& & MNF_SWIR4, & & \\
& & MNF_SWIR8 & & \\
\hline
\end{tabular}
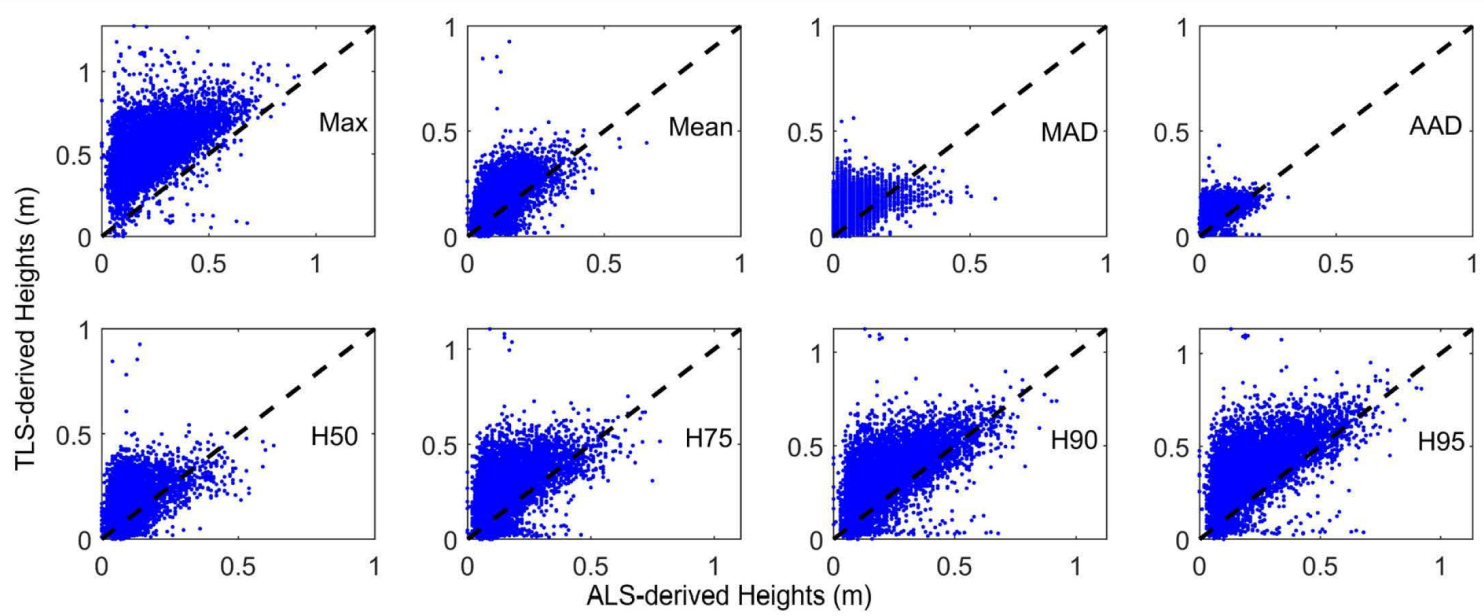

Figure 5. Comparisons of different height metrics from ALS and TLS data.
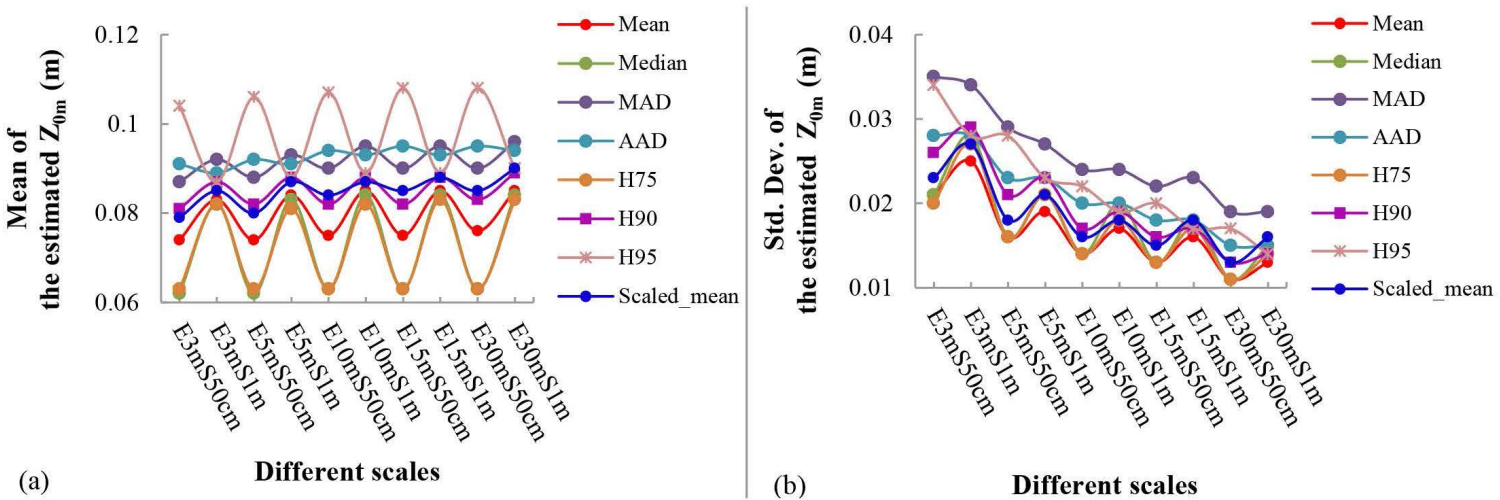

Figure 6 (a). The mean and (b) the standard deviation of the estimated $Z_{0 m}$ using different slice sizes and estimate scales using the MR1994 method. For example, E3mS50cm uses an estimate scale of $3 \mathrm{~m}$ and slice scale of $50 \mathrm{~cm}$. Results for max heights were not shown here because $Z_{0 m}$ estimations using max height were overestimated (larger than $0.15 \mathrm{~m}$ ). 


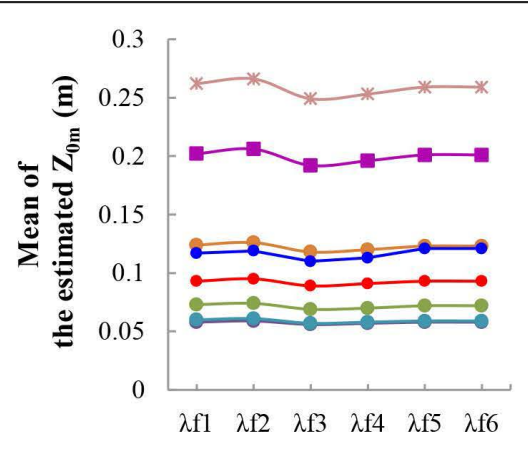

(a)

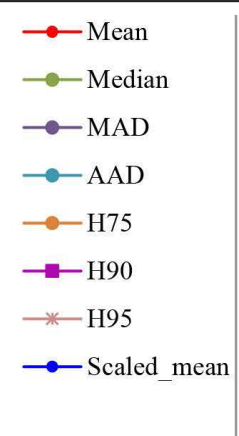

FAI

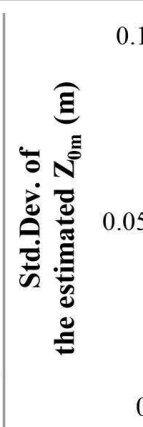

(b)

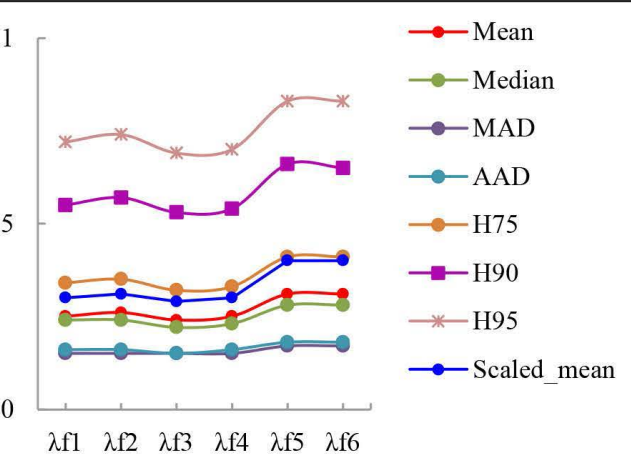

FAI

Figure 7 (a) The mean, and (b) the standard deviation of estimated $Z_{0 m}$ using RA1994. Results for max height were not shown here because $Z_{0 m}$ estimations were overestimated (larger than $0.4 \mathrm{~m}$ ).
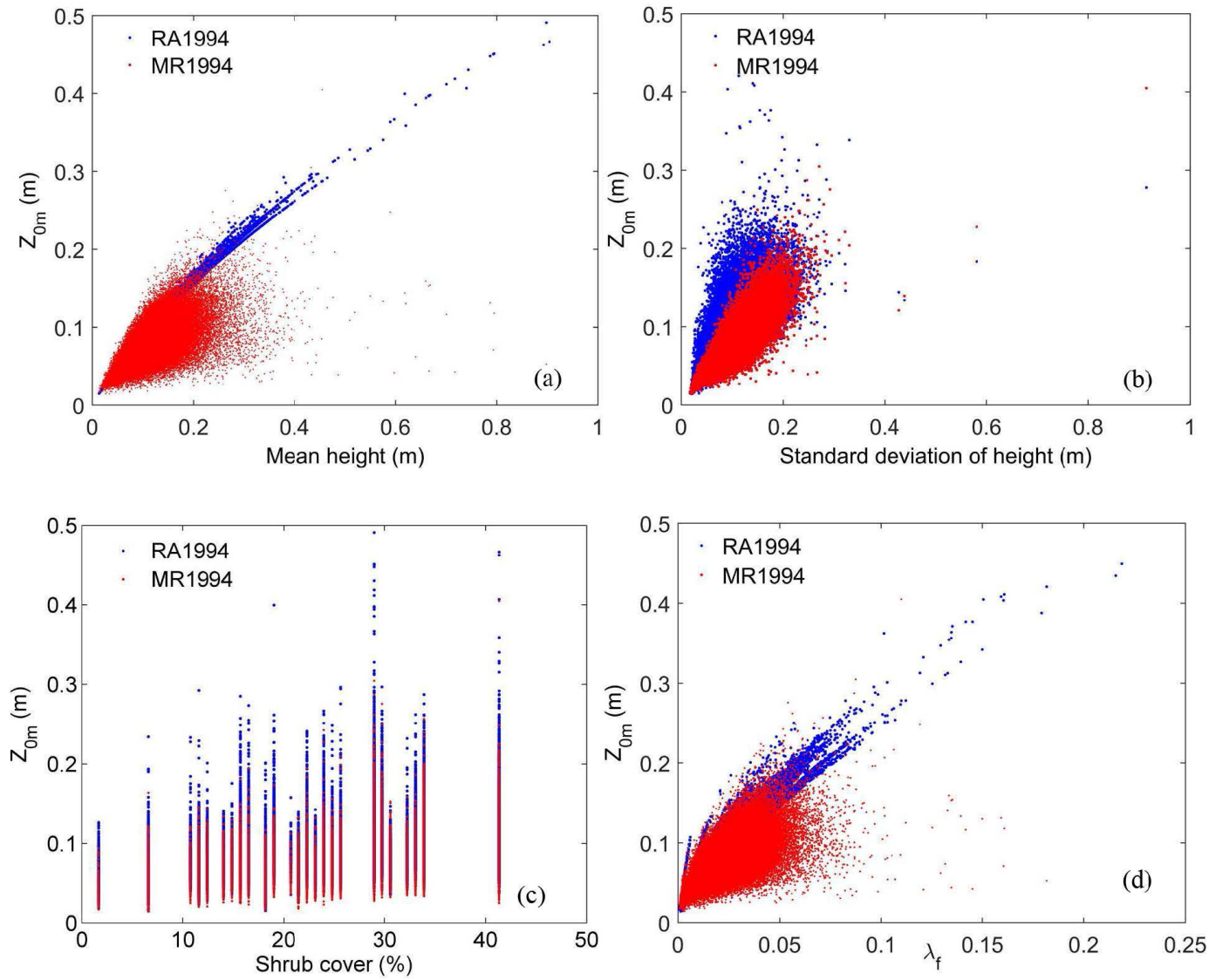

Figure 8. Scatterplots of $Z_{0 \mathrm{~m}}$ with (a) mean height, (b) standard deviation of height, (c) percent shrub cover, and (d) frontal area index $\left(\lambda_{f_{3}}\right)$.

Table 5. Variables in Table 4

Predictor variables Description

\section{From Lidar}

IQR Interquartile Range (IQR) of height of all lidar vegetation returns within

a pixel IQR $=$ Q75-Q25, where Q75 and Q25 are $75^{\text {th }}$ percentile and $25^{\text {th }}$ percentile.

MAD Same in Table 3

Veg_Cov

Percent ratio of lidar vegetation returns (greater than $0.15 \mathrm{~m}$ height) and total returns within a pixel

From Hyperspectral

ARI

$\mathrm{R} 2 \mathrm{G}$

Anthocyanin Reflectance Index $(A R I)=(800 *(1 / R 510)-(1 / R 700)$

GNDVI

PSRI

Red band and Green band Ratio (R2G) $=\mathrm{R}_{\text {red }} / \mathrm{R}_{\text {green }}$

MNF_SWIR4

Green Normalized Difference Vegetation Index (GNDVI) $=\left(\mathrm{R}_{\text {nir }}-\mathrm{R}_{\text {green }}\right) /\left(\mathrm{R}_{\text {mir }}+\mathrm{R}_{\text {green }}\right)$

MNF_SWIR8

Plant Senescence Reflectance Index (PSRI) $=($ R680 - R500 $) /$ R750

The fourth shortwave infrared (SWIR) band from the SWIR bands after MNF

The eighth shortwave infrared (SWIR) band from the SWIR bands after MNF 
using the two methods with mean height, standard deviation of height, PVC and FAI $\left(\lambda_{\beta}\right)$ (Figure 8). In comparison to the MR1994 method, the RA1994 method resulted in a larger range of $Z_{0 m}$ estimates and has a linear relationship with mean height and FAT.

When MAD was used to represent the roughness element height in RA1994, $Z_{0 m}$ using shrub cover is very similar to $Z_{0 m}$ using the total (shrub + grass) cover with $\mathrm{R}^{2}$ of 0.99 (Figure 9a). Thus the higher roughness element density due to the grass did not result in a higher $Z_{0 m}$ in this study. We explored this result by examining the histograms of the grass-dominated pixels ( $\mathrm{PVC}>75$ percent) in comparison to the histograms of shrub-dominated pixels (PVC $>35$ percent) (Figures $9 \mathrm{~b}$ and $9 \mathrm{c}$ ). The grass-dominated pixels have a lower mean value of $\mathrm{Z}_{0_{m}}$ than the shrub pixels due to the lower height of grass, even though grass cover is higher across this landscape.

Table 6. FAI $\left(\lambda_{f}\right)$ Calculations

\begin{tabular}{|c|c|c|c|c|c|c|}
\hline \multirow{3}{*}{$\begin{array}{l}\text { FAI } \\
\text { types }\end{array}$} & \multicolumn{2}{|c|}{ FAI calculation method } & \multicolumn{2}{|c|}{ FAI value } & \multicolumn{2}{|c|}{ FAI value } \\
\hline & \multicolumn{2}{|c|}{ Based on $\mathrm{F}_{\text {cover }}$} & \multicolumn{2}{|c|}{$\begin{array}{l}\text { using mean } \\
\text { height }\end{array}$} & \multicolumn{2}{|c|}{$\begin{array}{l}\text { using scaled } \\
\text { mean height }\end{array}$} \\
\hline & $\begin{array}{l}\text { Vegetation } \\
\text { cover }\end{array}$ & Shape & Mean & $\begin{array}{l}\text { Std. } \\
\text { Dev. }\end{array}$ & Mean & $\begin{array}{l}\text { Std. } \\
\text { Dev. }\end{array}$ \\
\hline$\lambda_{f 1}$ & Shrub cover & Cylinder & 0.021 & 0.009 & 0.028 & 0.012 \\
\hline$\lambda_{f 2}$ & Shrub cover & Cuboid & 0.020 & 0.008 & 0.025 & 0.010 \\
\hline$\lambda_{f 3}$ & $\begin{array}{l}\text { Shrub cover } \\
\text { +grass cover }\end{array}$ & Cylinder & 0.030 & 0.011 & 0.039 & 0.014 \\
\hline$\lambda_{f 4}$ & $\begin{array}{l}\text { Shrub cover } \\
\text { +grass cover }\end{array}$ & Cuboid & 0.027 & 0.009 & 0.034 & 0.012 \\
\hline \multirow{3}{*}{$\begin{array}{l}\text { FAI } \\
\text { types }\end{array}$} & \multicolumn{2}{|c|}{ FAI calculation method } & \multicolumn{2}{|c|}{ FAI value } & \multicolumn{2}{|c|}{ FAI value } \\
\hline & \multicolumn{2}{|c|}{ Based on $\mathrm{F}_{\text {section }}$} & \multicolumn{2}{|c|}{$\begin{array}{l}\text { using mean } \\
\text { height }\end{array}$} & \multicolumn{2}{|c|}{$\begin{array}{l}\text { using scaled } \\
\text { mean height }\end{array}$} \\
\hline & Cross-sections & Direction & Mean & $\begin{array}{l}\text { Std. } \\
\text { Dev. }\end{array}$ & Mean & $\begin{array}{l}\text { Std. } \\
\text { Dev. }\end{array}$ \\
\hline$\lambda_{j 5}$ & $\begin{array}{c}\text { Based on } \\
\text { cross-sections }\end{array}$ & NS & 0.024 & 0.002 & 0.024 & 0.002 \\
\hline$\lambda_{f 6}$ & $\begin{array}{c}\text { Based on } \\
\text { cross-sections }\end{array}$ & WE & 0.024 & 0.003 & 0.024 & 0.003 \\
\hline
\end{tabular}

\section{Comparison of Remote Sensing Data-Derived and Meteorological Data-Derived}

Figure 10 illustrates the cumulative turbulent source area and the $200 \mathrm{~m}$ buffer region around the towers in the study area, overlaid by $\mathrm{Z}_{\mathrm{om}_{m}}$ estimates based on the mean height using the RA1994 method. Heterogeneity in vegetation height is limited in this study area and thus calculating $Z_{0 m}$ as an average across the $200 \mathrm{~m}$ buffer had similar results as using the entire study area. Only slight differences were found between $Z_{0 m}$ estimates in the $200 \mathrm{~m}$ buffer and in the cumulative turbulent source area (Table 7 ). The remote sensing derived $Z_{0 m}$ values are larger than the multi-year ( 2 years) EC derived data (Table 7). However, the values are more similar when correlating the $\mathrm{Z}_{0 m}$ calculations from the eddy covariance measurements with the same dates as the remote sensing data collection $(05,06$, and 14 August 2010). The remote sensing derived $\mathrm{Z}_{0 \mathrm{~m}}$ ranges from 0.055 to $0.075 \mathrm{~m}$, with the minimum value closest to near neutral conditions (mean of 0.060 and std. dev. of 0.023 for $Z_{0 m}$ ) (Table 8, Figure 11). Mean $Z_{0 m}$ varies for neutral conditions $(0.060 \mathrm{~m})$, stable conditions $(0.048 \mathrm{~m})$, and unstable conditions $(0.039 \mathrm{~m})$ (Figure 11). The values of $Z_{0 m}$ derived from the CSAT EC data with wind speed larger than 3 $\mathrm{m} / \mathrm{s}$ had good agreement with $\mathrm{Z}_{0 \mathrm{~m}}$ values from CSAT EC data with all wind speeds at near neutral and unstable conditions (Table 8). Although the $\mathrm{Z}_{0 m}$ values from the remote sensing and RMYoung data are more similar, the smaller values of the CSAT data are expected to be more reliable than those from the RMYoung data (Greth et al., 2013) (Table 7).

\section{Discussion}

Variation between the multi-year EC data and remote sensing derived $Z_{0 m}$ values may be attributed to a number of reasons. For example, the multi-year EC data are averaged over seven years, whereas the remote sensing data observations come from an instantaneous observation at the end of the sevenyear period. The variations in $\mathrm{Z}_{0 m}$ highlight the differences in temporal and spatial resolution of the in situ and remote sensing data. Using the EC estimates from the time of remote sensing data collection (05, 06, and 14 August 2010) has a better correlation, but does not necessarily account for coarser time-scale variations. The lidar measurements across larger areas are complementary to the EC measurements which can represent $Z_{0 m}$ across a range of atmospheric conditions.

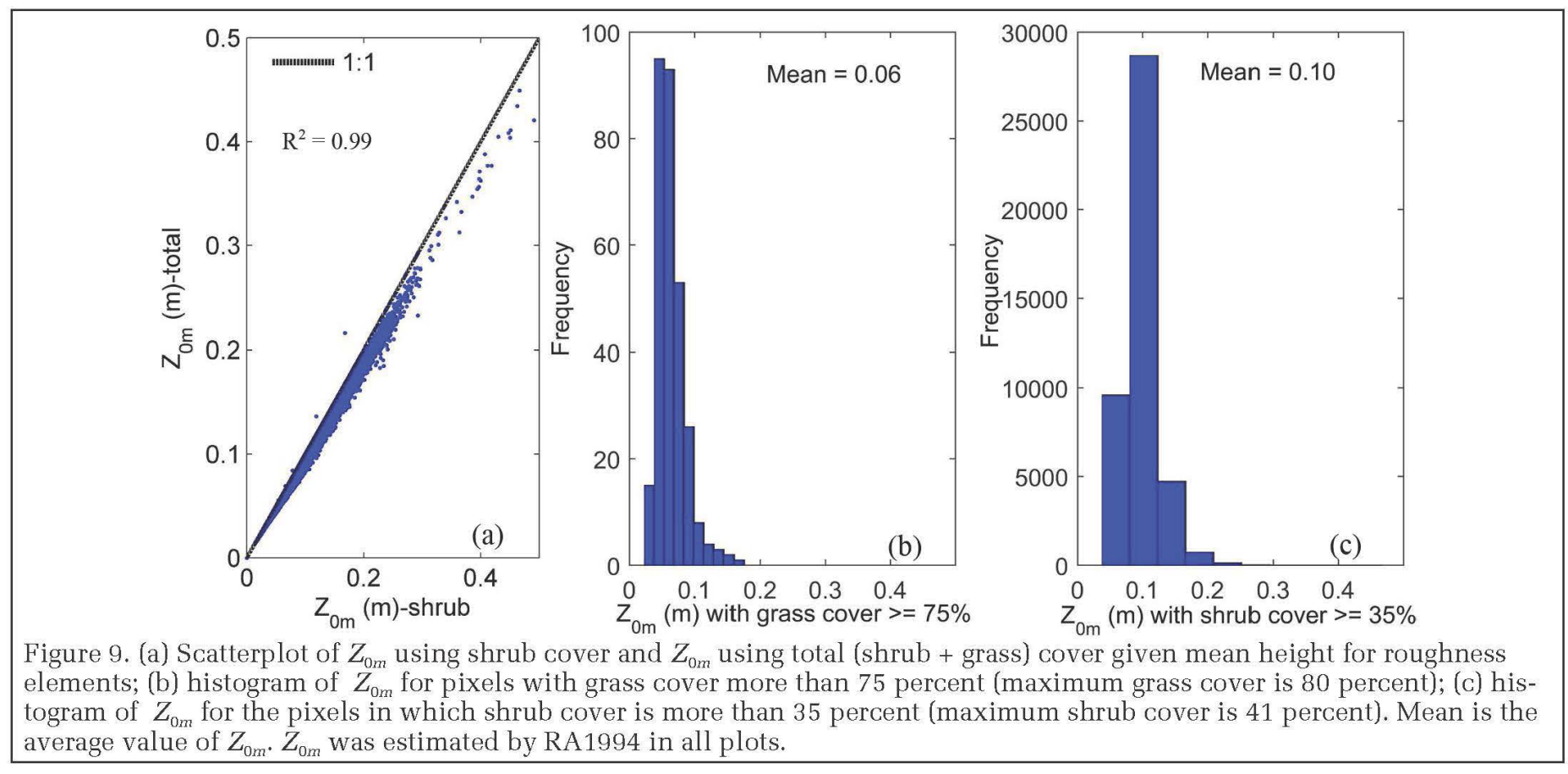


Table 7. Comparison of Remote Sensing Data Derived $Z_{0 m}$ (Based on Mean Height and MAD Height) and Multi-Year (2004 to 2010) EC Data Derived $Z_{0 m}$

\begin{tabular}{|c|c|c|}
\hline \multirow[b]{4}{*}{ Methods based on Remote Sensing } & $\mathrm{Z}_{0 m}(\mathrm{~m})$ & $\mathrm{Z}_{0 m}(\mathrm{~m})$ \\
\hline & Using & Using \\
\hline & mean & MAD \\
\hline & height & height \\
\hline RA1994: Site 1 Average over the source area & 0.072 & 0.060 \\
\hline Based on Site 1 Average over the $200 \mathrm{~m}$ buffer area & 0.069 & 0.057 \\
\hline lidar $+\quad$ Site 2 Average over the source area & 0.067 & 0.055 \\
\hline Site 2 Average over the $200 \mathrm{~m}$ buffer area & 0.069 & 0.057 \\
\hline MR 1094. Site 1 Average over the source area & 0.066 & 0.075 \\
\hline MR1994: Site 1 Average over the $200 \mathrm{~m}$ buffer area & 0.068 & 0.077 \\
\hline Site 2 Average over the source area & 0.065 & 0.071 \\
\hline Site 2 Average over the $200 \mathrm{~m}$ buffer area & 0.067 & 0.075 \\
\hline Method based on meteorological data & \multicolumn{2}{|l|}{$\mathrm{Z}_{0 m}(\mathrm{~m})$} \\
\hline Based on Site 1 RMYoung data & \multicolumn{2}{|l|}{0.055} \\
\hline EC data Site 1 & \multicolumn{2}{|l|}{0.042} \\
\hline EL data Site 2 RMYoung data & \multicolumn{2}{|l|}{0.044} \\
\hline
\end{tabular}

Table 8. $\mathrm{Z}_{0 \mathrm{~m}}(\mathrm{~m})$ Calculated from CSAT Eddy Covariance Measurements On 05, 06, and 14 August 5, 6 and 142010

\begin{tabular}{|c|c|c|c|c|c|c|}
\hline \multirow[b]{2}{*}{ CSAT data } & \multicolumn{3}{|c|}{ All wind speed data } & \multicolumn{3}{|c|}{$\begin{array}{c}\text { Data with wind } \\
\text { speed }>3 \mathrm{~m} / \mathrm{s}\end{array}$} \\
\hline & Mean & $\begin{array}{l}\text { Std. } \\
\text { Dev. }\end{array}$ & $\begin{array}{c}\text { Number } \\
\text { of } \\
\text { samples }\end{array}$ & Mean & $\begin{array}{l}\text { Std. } \\
\text { Dev. }\end{array}$ & $\begin{array}{c}\text { Number } \\
\text { of } \\
\text { samples }\end{array}$ \\
\hline $\begin{array}{l}\text { All } \\
\text { atmospheric } \\
\text { conditions } \\
\end{array}$ & 0.047 & 0.044 & 89 & 0.050 & 0.022 & 56 \\
\hline Near neutral & 0.060 & 0.023 & 20 & 0.060 & 0.023 & 20 \\
\hline Unstable & 0.048 & 0.025 & 37 & 0.047 & 0.021 & 32 \\
\hline Stable & 0.039 & 0.065 & 32 & 0.029 & 0.005 & 4 \\
\hline
\end{tabular}

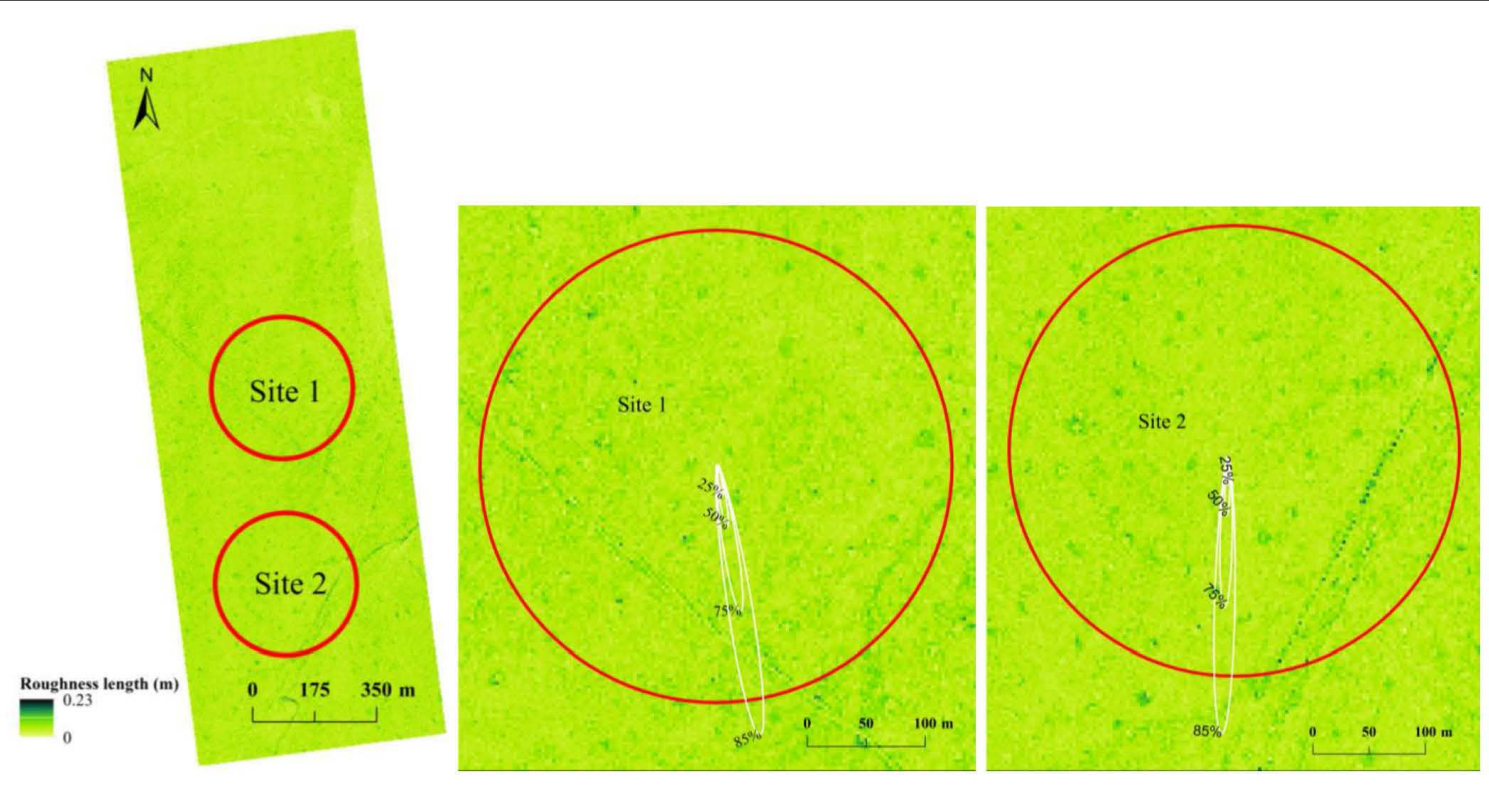

Figure 10. $Z_{0 m}$ estimates based on mean height using RA1994. The white outlines the cumulative turbulent source areas and the red circles are the $200 \mathrm{~m}$ buffer regions around the towers.

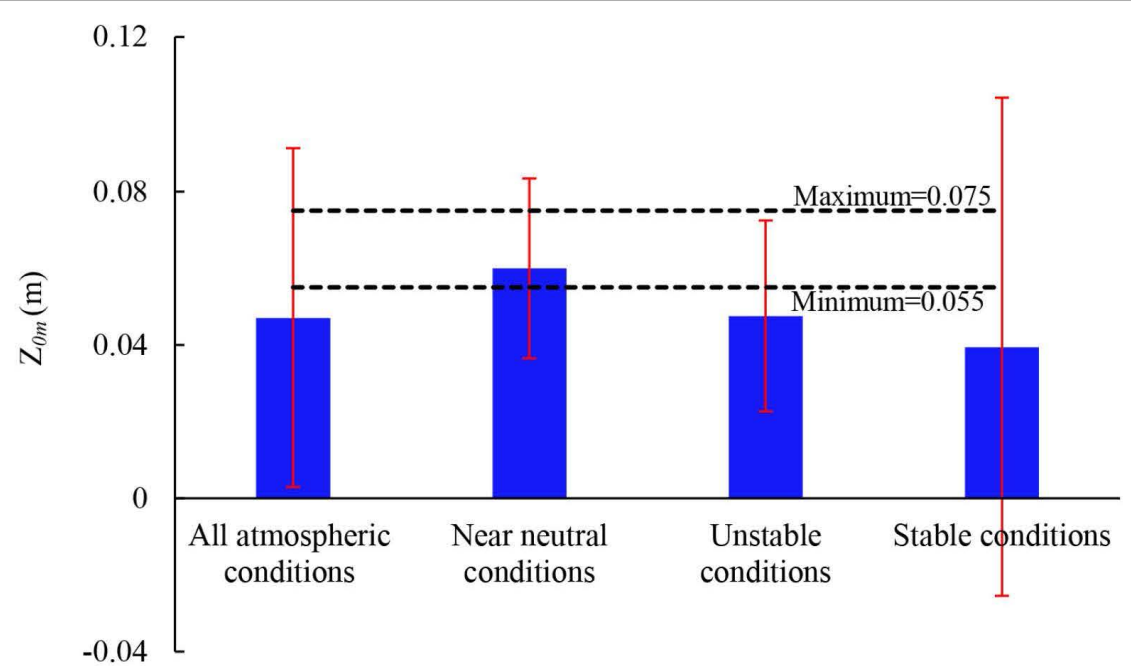

Figure 11. $Z_{0 m}$ derived from CSAT EC data at different atmospheric conditions. The maximum and minimum values are the range of $Z_{0 m}$ derived from remote sensing data (see Table 7). 
Similar to previous studies (Brown and Hugenholtz, 2012; Paul-Limoges et al., 2013), we found that the method used to calculate the height and standard deviation of height from lidar significantly influenced the $Z_{\text {orn }}$ estimation in the RA1994 method. However, there are no criteria for choosing a particular segment size or radius filter to make these calculations. In studies by Brown and Hugenholtz (2012) and Paul-Limoges et al. (2013), a filtering radius using a moving window was used to account for neighboring pixels for the vegetation height and its standard deviation. This procedure was utilized due to the effect of different filter sizes on the estimation of ground surface elevation from lidar (Wang et al., 2009). However, the filter radius method can also introduce noise generated from the neighboring pixels if they have large differences from the pixel of interest. Therefore, the filter radius method was not utilized in this paper and instead the estimation and slice scales were used to calculate vegetation height and its standard deviation. This approach allows consideration of height variability at the grid cell size of interest. In this paper, the $50 \mathrm{~cm}$ slice scale led to smaller and better results than the $1 \mathrm{~m}$ slice scale. The variability of height at coarser slice scales demonstrated large height differences in comparison to finer slice scales, where the variability of height can capture the relative variation of a shrub. The slice scale was selected in this study by balancing the point density and individual shrub size.

We also found that different lidar-derived height statistics resulted in differences in $\mathrm{Z}_{0 \mathrm{rm}}$ estimates and that the arithmetic mean height did not lead to the most accurate estimate of $\mathrm{Z}_{0 \mathrm{~m}}$. Mean height, median height, and H75 height resulted in better $Z_{0 m}$ estimates than other height metrics in the MR1994 model and median height resulted in the closest $Z_{0 m}$ value in comparison to the EC-derived $Z_{o m}$. However, mean, median, MAD, and AAD heights had better $Z_{0 \mathrm{rm}}$ estimation than other height metrics in the RA1994 model. Similar to Mitchell et al. (2015), MAD height proved to be a robust metric that captures the variability of the shrub height and resulted in $Z_{0 m}$ estimates closest to the EC-derived $Z_{0 m}$.

We assumed a limited amount of sagebrush growth from the one to two-year time gap between ALS and TLS data acquisitions (Zeng et al., 2008). However, a single scaling parameter did not account for variations in the differences between ALS and TLS mean heights among the pixels. Although the scaling parameter increased the magnitude of aerodynamic roughness, the results showed that the scaled height led to a larger bias than the un-scaled mean height when compared to the in-situ $\mathrm{Z}_{0 \mathrm{~m}}$. Interestingly, both $\mathrm{AAD}$ and $\mathrm{MAD}$, which capture the variability of height, had similar results in the RA1994 method (Figure 6) and provided the best estimates. We interpret that height variation rather than mean height serves an important role for calculating aerodynamic roughness, emphasizing the need to capture height variability across space with remote sensing. In contrast, in the MR1994 method the un-scaled mean height resulted in the aerodynamic roughness most approximate to the in-situ EC measurements. Compared to the RA1994 model, the MR1994 can be implemented more easily with only height-related information in a relatively homogenous area. However, in complex and heterogeneous areas where the frontal area index can be obtained, the RA1994 method may be more representative of $Z_{0 m}$. Although more driving parameters are needed for the RA1994 model, the sensitivity of these coefficients should be tested for different ecosystems. Additionally, a more accurate method would be to use higher density airborne lidar observations ( $>8$ points per $\mathrm{m}^{2}$ ) to potentially capture more accurate height variability. We used a $3 \mathrm{~m}$ spatial resolution for our analysis because this was the pixel size of the imaging spectroscopy data. A finer-scale pixel size could be used with lidar data of sufficient point density. However, sub-pixel analysis of the imaging spectroscopy data in this low vegetation cover ecosystem is challenging. In addition, because we used narrow-band indices for our spectroscopy analysis, a finer pixel-scale analysis will require collecting data at higher spatial resolution.

In addition to height, aerodynamic roughness varied along density, spatial pattern and geometry of roughness elements. However, we found that the $Z_{0 m}$ estimation using shrub cover had only small differences from that using total percent roughness element cover (shrub and grass cover). This may be due to the ALS mean height only capturing shrubs, as grass heights are within the vertical error of this small footprint lidar. Another reason that the grass had a low impact on the $\mathrm{Z}_{0 \mathrm{~m}}$ in our study area may be due to its low height, and thus lower resistance. Although the grass was accounted for in the frontal area index calculation, the ratio of the friction velocity and the wind velocity $\left(\frac{u_{*}}{U}\right)$ limited the increase of

$Z_{\text {om }}$ due to the increase of the cover percentage of roughness elements. Our results indicate that in this mixed shrub-grass community, the shrub component contributed the most resistance of roughness elements for wind and thus when using the cover percentage for the frontal area index estimates, grass cover is not necessary to include. The combination of lidar and hyperspectral data improved the vegetation percent cover estimates but had less improvement for shrub in comparison to grass (Mitchell et al., 2015; Glenn et al., 2016). Thus, in areas where imaging spectroscopy data cannot be obtained, especially where grass is sparse, lidar can be sufficiently used alone for shrub cover estimates and for frontal area index estimates of aerodynamic roughness.

In the RA1994 method, the roughness element density was equal to the percent vegetation cover in magnitude. However, the pattern of roughness elements cannot be interpreted from percent vegetation cover. In addition, the porosity of the vertical vegetation structure was not considered. Uncertainty was also introduced into the $Z_{0 m}$ estimates by using simplified cuboid and cylinder shapes to represent shrubs and the assumption of compaction of roughness elements. Further exploration on the shape and pattern of the roughness elements could be achieved by using finer-scale lidar data (higher point density and full-waveform) or a simulation approach to characterize both the vertical and horizontal structure of the canopy. More accurate percent vegetation cover could also enhance the frontal area index calculation and thus the aerodynamic roughness estimates.

\section{Conclusions}

Our study found that the roughness element height information from lidar can be used to map $\mathrm{Z}_{o m}$ across space. The RA1994 model represented the in-situ EC measurements better than the MR 1994 method, and is also more applicable in complex landscapes with varying geometry (e.g., grass, shrub, trees) when assessing the effects of different roughness elements on $Z_{o m}$. While we used imaging spectroscopy data to assist in deriving vegetation cover, we found that grass cover had a small effect on the overall $Z_{\text {om }}$ and can be excluded in $\mathrm{Z}_{\text {om }}$ calculations in this shrub-dominated area. Thus, modeling the shrub component is likely of more importance in similar ecosystems. Further, higher point density lidar ( $>8$ points per $\mathrm{m}^{2}$ ) could be used to estimate percent vegetation cover of shrub (Li et al., 2015) and thus reduce the dependency on imaging spectroscopy data in the RA1994 method. Conversely in areas where the vegetation cover is more heterogeneous, imaging spectroscopy data will assist with percent vegetation 
cover estimates (Kokaly et al., 2007), and thus contribute a more significant role. We will have additional opportunities to test and apply the RA1994 model to a range of ecosystems over time and space with the increasing availability of lidar data. Resultantly, land surface models will need to accommodate and test the refinement of $Z_{\text {orn }}$ estimates with remote sensing data. While regional availability of ALS is steadily increasing, two upcoming NASA missions, ICESat-2 (satellite) and GEDI (International Space Station), will provide photon counting and full-waveform datasets, respectively, across broader geographic regions albeit at coarser scales. The data from these missions will provide new opportunities to estimate $Z_{o m}$ across time and space.

\section{Acknowledgements}

Any use of trade, product or firm names is for descriptive purposes only and does not imply endorsement by the US Government. The work was supported by funding provided by NSF EAR 1226145 and EC data analysis supported by NSF Idaho EPSCoR Program and by the National Science Foundation under award number EPS-0814387.

\section{References}

Allen, R., A. Irmak, R. Trezza, J.M. Hendrickx, W. Bastiaanssen, and J. Kjaersgaard, J., 2011. Satellite-based ET estimation in agriculture using SEBAL and METRIC. Hydrological Processes, 25(26):40114027.

Bai, J., L. Jia, S. Liu, Z. Xu, G. Hu, M. Zhu, and L. Song, 2015. Characterizing the footprint of eddy covariance system and large aperture scintillometer measurements to validate satellite-based surface fluxes, IEEE Geoscience \& Remote Sensing Letters, 12 (5):943-947.

Bastiaanssen, W.G.M., 1995. Regionalization of Surface Flux Densities and Moisture Indicators in Composite Terrain, Ph.D. thesis, Agricultural University, Wageningen, The Netherlands,

Bastiaanssen, W.G.M., M. Menenti, R.A. Feddes, and A.A.M. Holtslag, 1998. A remote sensing surface energy balance algorithm for land (SEBAL), 1. Formulation, Journal of Hydrology, 212:198212.

Brown, O.W., and C.H. Hugenholtz, 2012). Estimating aerodynamic roughness (zo) in mixed grassland prairie with airborne LiDAR, Canadian Journal of Remote Sensing, 37:(4):422-428, URL: http://doi.org/10.5589/m11-051 (last date accessed: 18 April 2017).

Burian, S., M.J. Brown, and S.P. Velugubantla, 2002. Roughness length and displacement height derived from building databases, Proceedings of the 4th AMS Symposium on Urban Environment, pp. 131-132, URL: http://permalink.lanl.gov/ object/tr? what=infolanl-repo/lareport/LA-UR-02-1218 (last date accessed: 18 April 2017).

Choudhury, B.J., and J.L. Monteith, 1988. A four-layer model for the heat budget of homogeneous land surfaces, Quarterly Journal of the Royal Meteorological Society, 114(480):373-398, URL: http://doi. org/10.1002/qj.49711448006 (last date accessed: 18 April 2017).

Cocks, T., R. Jenssen, A. Stewart, I. Wilson, and T. Shields, 1998). The HyMap $^{\mathrm{TM}}$ airborne hyperspectral sensor: The system, calibration and performance, Versailles: European Association Remote Sensing Laboratories, URL: www.hyspex.no/ (last date accessed: 18 April 2017).

Colin, J., and R. Faivre, 2010. Aerodynamic roughness length estimation from very high-resolution imaging LIDAR observations over the Heihe basin in China, Hydrology and Earth System Sciences, 14(12):2661-2669, URL: http:/doi. org/10.5194/hess-14-2661-2010 (last date accessed: 18 April 2017).

Crookston, N.L., and A.O. Finley, 2008. yalmpute: An R package for kNN imputation, Journal of Statistical Software, 23(10):1-16. doi: $10.18637 /$ jss.v023.i10.
De Vries, A.C., W.P. Kustas, J.C. Ritchie, W. Klaassen, M. Menenti, A. Rango, A., and J.H. Prueger, 2003. Effective aerodynamic roughness estimated from airborne laser altimeter measurements of surface features, International Journal of Remote Sensing, 24(7):1545-1558, URL: http://doi. org/10.1080/01431160110115997 (last date accessed: 18 April 2017).

Dickinson, R.E., and A. Henderson Sellers, 1988. Modelling tropical deforestation: A study of GCM land surface parametrizations, Quarterly Journal of the Royal Meteorological Society, 114(480):439-462.

Garratt, J.R., 1992. Extreme maximum land surface temperatures, Journal of Applied Meteorology, 31(9):1096-1105.

Garratt, J.R.,1994. Review: The atmospheric boundary layer, Earth-Science Reviews, 37(1), 89-134, URL: http://doi. org/10.1016/0012-8252(94)90026-4.(last date accessed: 18 April 2017.

Glenn, N.F., L.P. Spaete, T.T. Sankey, D.R. Derryberry, S.P. Hardegree, and J.J. Mitchell, 2011. Errors in LiDAR-derived shrub height and crown area on sloped terrain, Journal of Arid Environments, 75(4):377-382, URL: http://doi.org/10.1016/j. jaridenv.2010.11.005 (last date accessed: 18 April 2017.

Greth, J., 2013. EPSCoR Evapotranspiration and Energy Balance Flux Site in Southern Idaho supports Hydroclimate Modeling., Masters thesis, University of Idaho, Moscow, Idaho.

Grimmond, C.S.B. and T.R Oke, 1999. Aerodynamic properties of urban areas derived from analysis of surface form, Journal of Applied Meteorology, 38(9):1262-1292.

Hiyama, T., M.Sugita, and Kotoda, 1996. Regional roughness parameters and momentum fluxes over a complex area, Journal of Applied Meteorology, 35(12):2179-2190.

Hopkinson, C., L.E. Chasmer, G. Sass, I.F. Creed, M. Sitar, W. Kalbfleisch, and P. Treitz, 2005. Vegetation class dependent errors in lidar ground elevation and canopy height estimates in a boreal wetland environment Canadian Journal of Remote Sensing, 31(2):191-206.

Hsieh, C.-I., G. Katul, and T. Chi, 2000. An approximate analytical model for footprint estimation of scalar fluxes in thermally stratified atmospheric flows, Advances in Water Resources, 23(7), 765-772, URL: http://doi.org/10.1016/S03091708(99)00042-1 (last date accessed: 18 April 2017).

Hugenholtz, C.H.,O.W. Brown, and T.E. Barchyn, 2013). Estimating aerodynamic roughness (z0) from terrestrial laser scanning point cloud data over un-vegetated surfaces, Aeolian Research, 10, 161-169, URL. http://doi.org/10.1016/j.aeolia.2013.03.004 (last date accessed 18 April 2017).

Jasinski, M.F., and R.D. Crago, 1999. Estimation of vegetation aerodynamic roughness of natural regions using frontal area density determined from satellite imagery, Agricultural and Forest Meteorology, 94(1):65-77.

Jia, L., Z. Su, B. van den Hurk, M. Menenti,A., Moene, H.A., De Bruin, and A. Cuesta, 2003, Estimation of sensible heat flux using the Surface Energy Balance System (SEBS) and ATSR measurements, Physics and Chemistry of the Earth, Parts $A / B / C, 28(1-3): 75-88$, URL: http://doi.org/10.1016/S1474-7065(03)00009-3 (last date accessed: 18 April 2017.

Jia, Z., S. Liu, Z. Xu, Y. Chen, and M. Zhu, 2012. Validation of remotely sensed evapotranspiration over the Hai River Basin, China, Journal of Geophysical Research: Atmospheres, 17, D13113, doi: 10.1029/2011JD017037.

Kaimal, J.C., and J.J. Finnigan, 1994. Atmospheric Boundary Layer Flows: Their Structure and Measurement, First edition, New York, Oxford University Press.

Kokaly, R.F., B.W. Rockwell, S.L. Haire, and T.V. King, 2007. Characterization of post-fire surface cover, soils, and burn severity at the Cerro Grande Fire, New Mexico using hyperspectral and multispectral remote sensing, Remote Sensing of Environment, 106(3):305-325.

Kustas, W.P., J.H. Blanford, D.I. Stannard, C.S. Daughtry, W.D. Nichols, and M.A. Weltz, 1994. Local energy flux estimates for unstable conditions using variance data in semiarid rangelands, Water Resources Research, 30(5):1351-1361. 
Kustas, W.P., B.J. Choudhury, M.S. Moran, R.J. Reginato, R. D. Jackson, L.W. Gay, and H.L. Weaver, 1989. Determination of sensible heat flux over sparse canopy using thermal infrared data, Agricultural and Forest Meteorology, 44(3):197-216, URL: http://doi.org/10.1016/0168-1923(89)90017-8 (last date accessed: 18 April 2017).

Lee, X., W. Massman, and B. Law, 2004. Handbook of micrometeorology: A guide for surface flux measurement and analysis, Kluwer Academic Publishers, pp.39-55 and pp. 119-158.

Lettau, H.,1969. Note on aerodynamic roughness-parameter estimation on the basis of roughness-element description, Journal of Applied Meteorology, 8(5):828-832 URL: http://doi. org/10.1175/1520-0450(1969)008<0828:NOARPE $>2.0 . C O ; 2$ (last date accessed: 18 April 2017).

Li, A., N.F. Glenn, P.J. Olsoy, J.J. Mitchell, and R. Shrestha, 2015. Aboveground biomass estimates of sagebrush using terrestrial and airborne LiDAR data in a dryland ecosystem, Agricultural and Forest Meteorology, 213:138-147, URL: http://doi. org/10.1016/j.agrformet.2015.06.005 (last date accessed: 18 April 2017).

Macdonald, R. W., Griffiths, R. F., \& Hall, D. J. (1998). An improved method for the estimation of surface roughness of obstacle arrays. Atmospheric Environment, 32(11), 1857-1864, URL: http://doi.org/10.1016/S1352-2310(97)00403-2 (last date accessed: 18 April 2017).

Marticorena, B., P. Chazette, G. Bergametti, F. Dulac, and M. Legrand, 2004. Mapping the aerodynamic roughness length of desert surfaces from the POLDER/ADEOS bi-directional reflectance product, International Journal of Remote Sensing, 25(3):603-626, URL: http://doi.org/10.1080/0143116031000116976 (last date accessed: 18 April 2017).

Menenti, M., and J.C. Ritchie, 1994. Estimation of effective aerodynamic roughness of Walnut Gulch watershed with laser altimeter measurements, Water Resources Research, 30(5): 1329-1337, URL: http://doi.org/10.1029/93WR03055 (last date accessed: 18 April 2017).

Mitchell, J.J., N.F. Glenn, T.T. Sankey, D.R. Derryberry, M.O. Anderson, and R.C. Hruska, 2011. Small-footprint lidar estimations of sagebrush canopy characteristics, Photogrammetric Engineering \& Remote Sensing, 77 (5):521-530, URL: http://doi.org/10.14358/PERS.77.5.521 (last date accessed: 18 April 2017).

Mitchell, J.J., N.F. Glenn, T.T. Sankey, D.R. Derryberry, and M.J. Germino, 2012. Remote sensing of sagebrush canopy nitrogen, Remote Sensing of Environment, 124:217-223, URL: http://doi. org/10.1016/j.rse.2012.05.002 (last date accessed: 18 April 2017).

Mitchell, J.J., R. Shrestha, L.P. Spaete, and N.F. Glenn, 2015. Combining airborne hyperspectral and LiDAR data across local sites for upscaling shrubland structural information: Lessons for HyspIRI, Remote Sensing of Environment, 167:98-110, URL: http://doi.org/10.1016/j.rse.2015.04.015 (last date accessed: 18 April 2017).

Nield, J.M., J. King, G.F. Wiggs, J. Leyland, R.G. Bryant, R.C. Chiverrell, S.E. Darby, F.D. Eckardt, D.S. Thomas, L.H. Vircavs, and R. Washington, 2013. Estimating aerodynamic roughness over complex surface terrain, Journal of Geophysical Research: Atmospheres, 118:(12,948-12,961, URL: doi:10.1002/2013/D020632 (last date accessed: 18 April 2017).

Ottoni, T.B., A.D. Matthias, A.F. Guerra, and D.C. Slack, 1992. Comparison of three resistance methods for estimating heat flux under stable conditions, Agricultural and Forest Meteorology, 58(1-2):1-18.

Paul-Limoges, E., A. Christen, N.C. Coops, T.A. Black, and J.A. Trofymow, 2013. Estimation of aerodynamic roughness of a harvested Douglas-fir forest using airborne LiDAR, Remote Sensing of Environment, 136:225-233, URL: http://doi. org/10.1016/j.rse.2013.05.007 (last date accessed: 18 April 2017).
Pelletier, J.D., and J.P. Field, 2015. Predicting the roughness length of turbulent flows over landscapes with multi-scale microtopography, Earth Surface Dynamics Discussions, 3:11071142. doi:10.5194/esurf-4-391-2016.

Prigent, C., I. Tegen, F. Aires, B. Marticorena, and M. Zribi, 2005. Estimation of the aerodynamic roughness length in arid and semi-arid regions over the globe with the ERS scatterometer, Journal of Geophysical Research: Atmospheres, 110(D9), D09205, URL: $h$ ttp://doi.org/10.1029/2004JD005370 (last date accessed: 18 April 2017).

Prueger, J.H., W.P. Kustas, L.E. Hipps, and J.L. Hatfield, 2004. Aerodynamic parameters and sensible heat flux estimates for a semi-arid ecosystem, Journal of Arid Environments, 57(1):87100.

Raupach, M.R., 1992. Drag and drag partition on rough surfaces, Boundary-Layer Meteorology, 60(4):375-395, URL: http://doi. org/10.1007/BF00155203 (last date accessed: 18 April 2017).

Raupach, M.R., 1994). Simplified expressions for vegetation roughness length and zero-plane displacement as functions of canopy height and area index, Boundary-Layer Meteorology, 71(1-2): 211-216, URL: http://doi.org/10.1007/BF00709229 (last date accessed: 18 April 2017).

Sankey, J.B., N.F. Glenn, M.J. Germino, A.I.N. Gironella, and G.D. Thackray, 2010. Relationships of aeolian erosion and deposition with LiDAR-derived landscape surface roughness following wildfire, Geomorphology, 119(1-2):135-145, URL: http://doi. org/10.1016/j.geomorph.2010.03.013 (last date accessed: 18 April 2017).

Sankey, J.B., D.J. Law, D.D. Breshears, S.M. Munson, and R.H. Webb, 2013. Employing lidar to detail vegetation canopy architecture for prediction of aeolian transport, Geophysical Research Letters, 40(9), DOI: $10.1002 /$ grl.50356.

Shaw, R.H., and A.R. Pereira, 1982. Aerodynamic roughness of a plant canopy: A numerical experiment, Agricultural Meteorology, 26(1):51-65, URL: http://doi.org/10.1016/0002-1571(82)90057-7 (last date accessed: 18 April 2017).

Streutker, D.R., and N.F. Glenn, 2006. LiDAR measurement of sagebrush steppe vegetation heights, Remote Sensing of Environment, 102(1-2):135-145, URL: http://doi.org/10.1016/j. rse.2006.02.011 (last date accessed: 18 April 2017).

Sud, Y.C., J. Shukla, and Y. Mintz, 1988. Influence of land surface roughness on atmospheric circulation and precipitation: A sensitivity study with a general circulation model, Journal of Applied Meteorology, 27(9):1036-1054.

Tian, X., Z.Y. Li, C. Van der Tol, Z. Su, X. Li, Q.S. He, Y.F. Bao, E.X. Chen, and L.H. Li, 2011. Estimating zero-plane displacement height and aerodynamic roughness length using synthesis of LiDAR and SPOT-5 data, Remote Sensing of Environment, 115(9):2330- 2341

Watts, M.J., and C.L. Wambolt, 1996. Long-term recovery of Wyoming big sagebrush after four treatments, Journal of Environmental Management, 46(1):95-102.

Weligepolage, K., A.S.M. Gieske, and Z. Su, 2012. Surface roughness analysis of a conifer forest canopy with airborne and terrestrial laser scanning techniques, International Journal of Applied Earth Observation and Geoinformation, 14(1):192-203, URL: http://doi.org/10.1016/j.jag.2011.08.014 (last date accessed: 18 April 2017).

Webb, E.K., G.A. Pearman, and R. Leuning, 1980). Correction of flux measurements for density effects due to heat and water vapor transfer, Quarterly Journal of the Royal Meteorological Society, 106(447):85-100.

Zhao, W., R.J. Qualls, and P.R. Berliner, 2008. A two-concentricloop iterative method in estimation of displacement height and roughness length for momentum and sensible heat, International Journal of Biometeorology, 52(8):849-58. 